\title{
Filling the weight gap: Estimating body weight and BMI using height, chest and upper arm circumference of Swiss conscripts in the first half of the 20th century
}

\author{
Fabienne P Trueb ${ }^{1}$, Jonathan CK Wells ${ }^{2}$, Frank J Rühli ${ }^{3}$, Kaspar Staub ${ }^{3,4} *$, Joël Floris ${ }^{3,5} * \S$ \\ ${ }^{1}$ Medical Faculty, University of Zurich, Switzerland \\ ${ }^{2}$ Childhood Nutrition Research Centre, UCL Great Ormond Street Institute of Child Health, London, UK \\ ${ }^{3}$ Institute of Evolutionary Medicine, University of Zurich, Switzerland \\ ${ }^{4}$ Zurich Center for Integrative Human Physiology (ZIHP), University of Zurich, Switzerland \\ ${ }^{5}$ Department of History, University of Zurich, Switzerland \\ * These authors contributed equally to this work: Last authorship \\ § Corresponding author: Joël Floris, joel.floris@iem.uzh.ch
}

Acknowledgment: Frank Rühli (grantee), Kaspar Staub, and Joël Floris have received financial support from the Mäxi Foundation. Kaspar Staub and Joël Floris have received financial from the Swiss National Science Foundation (Project No. 156683).

Keywords: BMI, Weight, Anthropometrics, Great Depression, World Wars,

\begin{abstract}
:
We estimate weight and BMI values based on height, chest circumference, and mid upper arm circumference measures of Swiss conscripts in the city of Zurich for each year between 1904 and 1932. Height, chest circumference, and mid upper arm circumference were measured each year from 1904 to 1951. Body weight is available from 1933 to 1951 . We used prediction equations from the literature, and also developed our own equations, which we tested and validated on the dataset from 1933 to 1951 . We used a representative sample of usually 19 -year-old Swiss males $(N=88,792$, coverage $>88 \%)$. There was an increase in average height and chest circumference between 1904 and 1951. During both world wars, chest circumference, mid upper arm circumference, weight, and BMI decreased, while height stagnated. Overall mean weight and BMI increased from 1904 to 1951, but decreased during the Great Depression. After World War II, weight quickly returned to the pre-war and pre-Great Depression level, while BMI had not reached the 1933 level by 1951. Average weights of the lower and middle socioeconomic groups were catching up with average weight of the upper socioeconomic group from 1904 to 1951. The convergence in height is less pronounced. Finally, we show that it is possible to accurately predict mean weight and BMI from other anthropometric measurements. We suggest that our estimation approach could be replicated for other historical populations to obtain more information on how nutritional status changed over time.
\end{abstract}




\section{Introduction}

Anthropometric measurements assess the size, proportions, and composition of the human body, and are common external indicators of nutritional status (Willett and Hu 2012; WHO Expert Committee 1995). Because nutritional status is an important part of human health, growth in children and body dimensions at all ages also reflect the overall health and welfare of individuals and populations (WHO Expert Committee 1995). Therefore anthropometric measurements are used to determine the inclusion of individuals, families, and communities in intervention programs to improve nutrition and health in general, as well as to evaluate those interventions (WHO Expert Committee 1995).

Changes in the size and shape of the human body can be linked to various environmental changes (Ruff 2018b; Floud et al. 2011). The reconstruction of body size and shape of past populations is a major focus in archaeological and anthropological research (Ruff 2018a; Steckel and Rose 2002). It is used to infer behaviour, based on long-bone structure, and to study the impact of changes in climate and nutrition on the human body. One main emphasis is to assess health status using variation in stature (Ruff 2018a). Changes in average height have also been widely used in anthropometric history as a marker of changes in living standards (Floud et al. 2011; Steckel 2009). In both Ruff and Floud et al., stature as well as weight and BMI are analysed (Ruff et al. 2018; Carson 2016; Floud et al. 2011; Ruff et al. 2005). While in archaeological and anthropological research, weight and BMI values have been estimated indirectly from skeletal remains, studies in anthropometric history have relied on historical sources to provide direct weight measurements.

In both cases, sample size has often been small, not least because direct weight measurements are scarce compared to height records. In addition, there is little information on weight and BMI values of a representative sample of young people who are generally healthy. To our knowledge, no studies have reconstructed and estimated body weights based on other available anthropometric measurements for a period of several years and for a representative historical population living in the first half of the 20th century. The existing studies in anthropometric history are either based on available weight measurements from the late 19th century, or on specific subpopulations like cadets, boarding school children or prisoners (Komlos and Carson 2017; Komlos and Brabec 2010).

Therefore, it is still largely unclear how BMI values developed in historical populations in the first half of the 20th century, which included boom times and economic crises, as well as two world wars (Komlos and Carson 2017). In Switzerland, there was an above average increase in GDP per capita since the end of the 19th century, making Switzerland one of the richest countries in the world by World War I (Floris, Höpflinger, et al. 2019). At the same time, Swiss on average became taller and experienced increased life expectancy, though in contrast to GDP per capita, they were not at the top of European rankings for height or life expectancy at birth (Floris, Höpflinger, et al. 2019). The same is true for real wages. The increase is evident and Switzerland was no longer a low-wage country by World War I, but in comparison Swiss purchasing power was not higher than abroad. Living standards increased steadily until 
1950, with noticeable but short-term decreases or stagnation during the two world wars and the Great Depression. Weight and BMI reflect the immediate nutritional conditions while height is the result of the cumulative net nutrition over the entire growth years. Thus, it is interesting to analyse how weight and BMI have developed relative to the increase in height and other well-being indicators during an erratic period when war, economic growth and economic crisis alternated and the welfare state expanded (Rosenberg 2012).

The short-termed impact of World War I on birth weights, as well as on height and upper arm circumference of school children has already been analysed for some regions in Switzerland (Staub 2016; Floris, Staub, and Woitek 2016). In addition, the development of height, BMI, chest circumference and right upper arm circumference of conscripts has been studied for cross-sectional Swiss conscripts data (years: 1875-1879, 1933-1939, 1994-2014) (Staub et al. 2016; Schoch, Staub, and Pfister 2012; Staub et al. 2010). A rising trend in $\mathrm{BMI}$ values was observed over the course of the 20th century using three cross-sections from the 1870s, the 1930s and 2014: average BMI among conscripts raised from $20.63 \mathrm{~kg} / \mathrm{m} 2$ in the 1870 s to 23.29 kg/m2 in 2014 (Staub et al. 2016; Schoch, Staub, and Pfister 2012; Staub et al. 2010). In the 1870s and 1930s, weight and BMI values were almost symmetrically distributed (Staub et al. 2016). In the 1870s, $12.1 \%$ of the young Swiss conscripts were underweight, $1,6 \%$ overweight, and $0.1 \%$ obese by modern standards, whereas in 2014 5.5\% were underweight, 18.4\% overweight and 5.7\% obese (Staub et al. 2016).

In the case of these anthropometric data analysed for Switzerland, however, there is a large time gap in the data for body weight measurements between 1880 and 1932 (the army did not consider body weight to be an important measure of nutritional status and military fitness at the time). In this paper, we aim to fill this weight gap and estimate weight and BMI based on height, chest circumference and mid upper arm circumference measures of Swiss conscripts in the city of Zurich for each year between 1904 to 1932. We used existing anthropometric prediction equations from the literature and developed equations that we tested and validated on our 1933 to 1951 dataset, which includes body weight data. This makes it possible to investigate changes in mean weight and $\mathrm{BMI}$ in the first half of the $20^{\text {th }}$ century for a representative sample of young urban adults on a yearly basis. 


\section{Methods}

\section{Data}

We analyse yearly data of young men conscripted in the city of Zurich between 1904 and 1951. Since 1875, every 19-year-old male Swiss citizen has been called up for conscription (Kurz 1985). The anthropometric data were recorded during the medical examination for military fitness (regardless of whether the person was fit for military service or not). These records of the city's military command are kept in Zurich's city archives (records prior to 1904 were not preserved in the archives). The complete anthropometric data of 99,912 conscripts from the written military control books were transcribed in anonymised form (without name, exact birth date and residential address) during the course of a historical dissertation at the Department of History of the University of Zurich between years 2007 to 2012 (Floris 2016). Permission was granted by the archive of Zurich and data protection contracts were signed. According to the Federal Act on Research involving Human Beings and the Ethical Commission of the Canton of Zurich, no ethical approval is needed for anonymously collected or anonymised health-related historical data (HRA 1 January 2014, Art. 2).

The medical examination at recruitment was prescribed in details in military instructions manuals (Schweizerische Armee 1887; 1932; 1941; 1952). The standardised procedure did not change over time. The procedure started with the measurement of height, followed by chest circumference and mid upper arm circumference and ended with the measurement of weight. However, weight was only measured from 1875 to 1879 and then again after 1932. Height was recorded with a portable device. Participants stood flat on their bare feet with the heels together and heels and the back of head touching the measuring rod. For chest circumference, the measuring tape was set snug around the naked chest in a horizontal line just below the nipples. The measurement was taken in between two breaths. Mid upper arm circumference was measured in the middle of the extended right upper arm. Participants were weighed while wearing trousers or underwear, presumably with a mechanical scale.

Since military service was and still is mandatory in Switzerland, we have a representative sample of the 19-year-old Swiss men living in the city of Zurich. A previous study estimated that in the conscription years 2004 to 2012, at least 91 per cent of the birth cohorts were recorded in the conscription data (Panczak et al. 2013), and this coverage was presumably even higher in the first half of the $20^{\text {th }}$ century (Schoch, Staub, and Pfister 2012). We estimate a coverage of $>88$ per cent for the city of Zurich in the census and conscription year 1920. For this paper, conscripts age 22 or older $(10,438(10.4 \%))$ were excluded, as they are not considered regular conscripts and appeared at conscription with long delays. 5 conscripts older than 22 are excluded from the 1933 data $(\mathrm{min})$ and 523 are excluded from the 1932 data (max), on average 217 conscripts are excluded per year). 
On average, 1930 conscripts were measured per year (min 1126; max 3555). The number of conscripts per year increased over time because of increasing population. The legally stipulated age for recruitment was 19 between 1904-1951. Therefore, most of the conscripts in the dataset were aged between 19-20 (56 percent of all conscripts in our dataset, see Appendix Table 5). There were, however, deviations in this legal regulation during the period of observation (Floris 2016). In 1919 there was only limited conscription of old pending cases $(n=318)$. This was due to the influenza epidemic of 1918 and military budget issues after the war. Regular conscription took place from 1920, and until 1924, the majority of conscripts were 20 years old. The conscription age gradually returned to 19 from 1925 on. In 1928 about the same number of 19- and 20-year-olds were conscripted, and in 1930 only 19-year-olds were conscripted. In 1939 two conscription rounds took place: a regular one from February to July, and a warrelated one in the winter of 1939/40 (November/February). During the war the conscription age was 18 . In 1946 ( $n=363$ ), as in 1919, conscription did not occur. Conscription age returned to 19 from 1947 onwards. Comparisons between cohorts should bear in mind these differences in conscription age. We do not know the exact date of birth of the conscripts. The age variable is based on the difference between the year of conscription and the year of birth. The chronological age difference of two 19-year-olds in our dataset can therefore be one year. This paper includes the anthropometric data of 88,792 conscripts obtained each year between 1904-1951, with the exception of 1919 and 1946.

Conscripts' occupations were recorded during conscription. We used this information to assign each conscript to a social stratum on the basis of Schüren's classification (Schüren 1989), which is based on criteria such as typical income, wealth and prestige of the occupation. This occupational social hierarchy consists of three levels: low, middle and upper socioeconomic position (SEP). The SEP of a conscript is a good proxy for socio-economic background (Schoch, Staub, and Pfister 2012). In our dataset 50,538 (56.9\%) conscripts had a low SEP, 24,979 (28.1\%) a middle SEP and 11,520 (13.0\%) an upper SEP. 1755 (2.0\%) remaining conscripts were either farmers, lacked an occupation or could not be assigned to a specific SEP.

The lower SEP group consists of day labourers, unskilled and skilled workers. The middle SEP group consists of commercial employees, white-collar workers, and lower civil servants. The upper SEP group consists of students in higher education schools and universities. At the beginning of our observation period, 50 to 55 percent of the conscripts are in the lower SEP group. The share of the lower SEP group increases to 60 to 65 percent in the 1920s. This is equivalent to an increase of 250 to 500 conscripts. 30 to 35 percent of the conscripts are in the middle SEP group. In the 1920s the share decreases to 25 percent. The share of the upper SEP group remains constant over time (Figure 6).

\section{Reconstruction based on equations from the literature}

The measurement of mid upper arm circumference allows for a fast estimation of malnourishment and $\mathrm{BMI}$, even though there is no universally accepted cut-off value as a screening criterion for identifying severe acute malnutrition (Tang et al. 2013). For adults and elderly people, the available equations differ in 
the variables used for weight estimations and they show different degrees of accuracy (Balode et al. 2015; Melo Ferreira et al. 2014). Our literature review found seven prediction equations from six publications (Table 1) that are based on the same variables that we use (height, chest circumference, mid upper arm circumference). Sultana et al. (2015), Powell-Tuck and Hennessy (2003), and Benítez Brito et al. (2016) used mid upper arm circumference to calculate BMI (or vice versa), partially corrected for age. Even though all of these studies measured mid upper arm circumference at the midpoint between olecranon and acromion on the non-dominant (or left) side, equations to calculate BMI using this data vary considerably. Cattermole et al. (2017) calculated weight using a formula with right mid upper arm circumference. Ostechega et al. (2004) provides a formula for estimating mid upper arm circumference using weight, height and age; we rearranged this equation to make weight the subject of the formula. Chest circumference and height are used in the equation introduced by Chittawatanarat et al. (2012).

\section{Table 1: Equations from the Literature}

\section{Reconstruction based on own equations}

We developed weight and BMI regression equations using the conscription records from 1933 to 1938 (11,223 conscripts, $12.6 \%$ of the total dataset). These are the earliest years in these records that include weight measurements. We performed stratified random sampling to divide this dataset into a training dataset $n=5609$ and a test dataset $n=5614$ (using the sample_frac() function from the R dplyr package). We stratified according to SEP, age and measurement year (=conscription year). Summary statistics for height for the training and the test datasets are reported in Table 6 in the appendix. First, we estimated three simple linear regression equations on the training dataset. The dependent variable weight was regressed on each predictor variable separately (height, chest circumference, mid upper arm circumference, see the resulting regression equations in Table 7 in the appendix). In a second step we predicted weight for each conscript on the basis of those three regression equations, which resulted in three weight estimates per conscript. Finally, in a third step we calculated the arithmetic mean of those three predicted weight values. The basic idea behind this procedure is that every anthropometric predictor variable is correlated with weight. Both the accuracy of the predictive value, i.e. how close each prediction value is to the actual value, and the precision of the three prediction values, i.e. how close the prediction values are to each other, will differ, but the arithmetic mean of those three predicted values will be quite accurate, as the error should cancel out (Wells et al. 2009). We also predicted weight using multiple linear regression equations that include all combinations of our predictor variables. The same procedure was used to directly predict and estimate BMI values.

The resulting equation were tested on the test dataset 1933-1938. All equations were further validated on the conscription years 1947-1951 (where weight was also available) to see if they were accurate in a different time period. Finally, we compared our results with the equations from the literature. We used two criteria to evaluate the accuracy of the predicted values. First, the arithmetic mean of the 
estimated values should not differ more than $1 \mathrm{~kg}$ from the true mean weight in the dataset or $0.5 \mathrm{~kg} / \mathrm{m} 2$ from the true BMI values. Second, more than $85 \%$ of the estimated values should lie within a $10 \%$ interval around the true value. The second criterion focuses on the individual estimations, while the first criterion focuses on an accurate average estimation. We used the multiple regression equations with all predictor variables to estimate the missing weight (WCAH equation) and BMI (BMICAH equation) between 1904 and 1932. Both equations performed better in regards to the second criterion than the first. Figure 8 and Figure 9 in the appendix show scatterplots and Bland-Altman-plots using the WCAH equation for weight estimation and the BMICAH equation for BMI estimation. 


\section{Results}

\section{Descriptive results of measured data}

In Figure 1 we show changes in average for height, chest circumference and mid upper arm circumference between 1904 and 1951, as well as for weight and BMI between 1933 and 1951 (for summary statistics for selected years see Table 9 in the appendix). Over this time period average height increased steadily from $167.2 \mathrm{~cm}(95 \% \mathrm{Cl}: 166.7-167.6 \mathrm{~cm})$ to $173.4 \mathrm{~cm}(95 \% \mathrm{Cl} 173.2-173.7 \mathrm{~cm})$, and chest circumference from $84.6 \mathrm{~cm}(95 \% \mathrm{Cl} 84.3-84.9 \mathrm{~cm})$ to $90.0 \mathrm{~cm}(95 \% \mathrm{Cl} 89.9-90.2 \mathrm{~cm})$. There was a less pronounced increase in average mid upper arm circumference from $24.75 \mathrm{~cm}(95 \% \mathrm{Cl}: 24.64-24.86 \mathrm{~cm})$ to $25.77 \mathrm{~cm} \mathrm{(95 \%} \mathrm{Cl:} 25.69$ $-25.84 \mathrm{~cm})$. During both world wars, chest and mid upper arm circumference decreased while height stagnated.

Both average weight and BMI decreased during the Great Depression and World War II. After the war, average weight returned to the pre-war and pre-Great Depression level (1933: 64.03kg, 95\% Cl: $63.69-$ 64.37kg; $1951: 63.90 \mathrm{~kg}, 95 \% \mathrm{Cl}: 63.62-64.18 \mathrm{~kg})$. BMI also recovered after the war but the pre-crisis level of 1933 had not been reached by 1951 (1933: $21.79 \mathrm{~kg} / \mathrm{m} 2,95 \% \mathrm{Cl}: 21.70-21.89 \mathrm{~kg} / \mathrm{m} 2 ; 1951: 21.23 \mathrm{~kg} / \mathrm{m} 2$, 95\% Cl: 21.15 - 21.31 kg/m2). In 1933, 54 conscripts (3.02\%) had a BMI below 18.5kg/m2, 1642 (91.73\%) between 18.5 and $25 \mathrm{~kg} / \mathrm{m} 2$, and $93(5.20 \%)$ above $25.0 \mathrm{~kg} / \mathrm{m} 2$. The percentage distribution was similar in 1951 (see Table 10 in the appendix). Histograms and kernel density estimation curves for height, chest circumference, mid upper arm circumference, weight and BMI in 1933 are shown in Figure 11 in the appendix. All distributions appear symmetrical, and the height distribution in particular indicates heaping at numbers ending in 0 or 5 .

\section{Figure 1: Mean changes in anthropometric measures among conscripts 1904 to 1951 (measured values)}

\section{Estimate accuracy, test and validation}

Next, we evaluated the accuracy of our own estimation equations and compared them with the estimates using the equations from the literature. The results for our own equation are presented in Table 2, and those from the literature in Table 11 in the appendix. Our own estimates of the mean weight are more accurate than those resulting from the literature equations. We under or overestimate the true mean weight by less than $3 \%$ (less than 1.9kg difference) in the test dataset (1933-1938) and validation dataset (1947-1951). One of our own equations fails to meet the second criterion (more than $85 \%$ of the estimates within a $10 \%$ interval around the true value). None of the equations from the literature meet the second criterion. 
The results for our own equation for BMI are presented in Table 3 and those of the literature in Table 12 in the appendix. Our own estimates under or overestimate the true mean BMI by less than 3\% (less than $0.65 \mathrm{~kg} / \mathrm{m} 2$ difference) in the test dataset (1933-1938) and the validation dataset (1947-1951). Two estimations do not meet the second criterion (more than $85 \%$ of the estimates within a $10 \%$ interval around the true value). The literature BMI estimation equations work better than those for weight estimation, but only the Powell-Tuck and Hennessy (2003) (not age corrected) equation for BMI meets both criteria in both datasets.

Table 2: Own equation estimation accuracy weight $(\mathrm{kg})$

\section{Table 3: Own equation estimation accuracy BMI (kg/m2)}

For the trend estimations of weight and BMI presented in the next section, we used the equations that performed best according to the second criterion (more than $85 \%$ of the estimates within a $10 \%$ interval around the true value). For the weight reconstruction we used our WCAH equation and for BMI reconstruction we used our BMICAH equation. The agreement between measured and estimated weight and BMI values from the test data set 1933-1938 is presented in the Appendix Figures 4 and 5. Although there is some variation in the accuracy of individual values, the overall mean is predicted with precision (Appendix Figure 5). These Bland-Altman plots also show that we underestimate large weight and BMI values in particular (the smoothed trend lines deviate towards lower estimated than measured values). That is why we slightly underestimate the measured mean value in a small decimal range.

\section{Estimated trends of weight and BMI}

Figure 2 shows estimates of mean weight for the entire period 1904 to 1951, calculated with our own equation WCAH (the equation with the best performance regarding the second criterion: Numbers of values in a 10 percent range). The figure includes the mean weight values of the dataset with recorded weights (1933 to 1951). Mean weight increased over time. The increase was most pronounced in the 1920s, while there was a decrease during the 1930s and during both world wars. In addition, the figure shows mean weight estimates (WCAH equation) for the three socioeconomic groups (SEP) from 1904 to 1951. The lower SEP and middle SEP groups have similar mean weights. In 1904, the upper SEP group was about $5 \mathrm{~kg}$ heavier than the other groups. The difference decreased steadily and in 1951 the upper SEP group was only slightly heavier than the other groups. Mean weight increased over time by $8 \mathrm{~kg}$ for the low and middle SEP groups, and $5 \mathrm{~kg}$ for the upper SEP. The negative impact of both world wars is visible for all three groups.

Figure 2: Estimated mean weight and SEP differentiated mean weight 1904-1951 (WCAH equation)

Figure 3 shows average BMI estimates for the time period 1904 to 1951. For the estimation, the BMICAH equation was used (the equation with the best performance regarding the second criterion: No. of 
values in a 10 percent range). The figure includes the mean BMI values of the dataset with recorded weights (1933 to 1951). BMI increased slightly over time, with increase being most pronounced in the 1920s. Mean BMI decreased in both world wars and in the 1930s. In addition, the figure shows mean BMI estimates (BMICAH equation) for the three socioeconomic groups (SEP) from 1904 to 1951. The lower SEP group had the highest BMI values. The middle and upper SEP show similar average BMI values. However, average BMI values of the upper SEP group were generally slightly higher. Again, the impact of both world wars is visible for all three groups.

Figure 3: Estimated mean BMI and SEP differentiated estimated mean BMI 1904-1951 (BMICAH equation) 


\section{Discussion}

This paper estimates weight and BMI values based on height, chest circumference and mid upper arm circumference. First, we linearly regressed $\mathrm{BMI}$ and weight using different combinations of predictor variables with a training dataset from the 1930s. Second, we tested and validated the resulting equations on a test dataset and a different validation dataset. We then compared our estimates with estimates using equations proposed in the literature. We used the best equation to estimate missing weight and BMI values from 1904 to 1932. We show that weight and BMI can be estimated with accuracy using height, chest circumference and mid upper arm circumference. It allows us to reconstruct changes and trends in weight and BMI for a young, healthy, urban male population and for SEP subgroups. And it allows us to assess the impact of World War I on weight and BMI.

\section{Data}

The data was recorded as part of the compulsory military conscription in Switzerland from 1904 to 1951. The measurement procedures were described in detail in instruction books and remained the same for the whole period. Since several people carried out the procedure, a high compliancy with the protocol can be assumed. However, the data were not recorded for scientific purpose. Therefore, no stated effort was made to reduce possible measurement error. But the following of a standardized examination procedure would have minimized measurement errors.

We used a large representative sample of young Swiss males (between 18 and 21 years old) who lived in an urban environment. The changes over time are mainly caused by changes in the environment and not by changes of the study population. The high comparability of the study population over time is important for being able to obtain accurate estimation equations. Migration patterns, however, could still have had an impact on the study population. It is especially true for the years before World War I when immigration to Switzerland was more important than in the interwar period and during both world wars. The results in this paper apply only to the particular group of young males with Swiss citizenship living in an urban area.

Zurich attracted a constant rate of internal migration. The net migration gain was driven by Swiss citizens from other cantons (Statistisches Amt der Stadt Zürich 1951). The most important age classes were 15-19, 20-24, and 25-29 years (Statistisches Amt der Stadt Zürich 1929; 1951). Rough calculations give a worst-case scenario of 10 percent more conscripts annually due to internal migration. We are not able to assess the potential bias. We know whether those conscripts came from rural or urban areas, but not the age at which a conscript settled in Zurich. In Switzerland, place of birth is usually not recorded in official documents. Thus, we are not able to differentiate between the immigrant conscripts from those born in Zurich. The changes in the SEP distribution reflect changes in society and are probably related to the issue of internal migration. The majority of people worked in the industrial sector or were tradesmen 
(Statistisches Amt der Stadt Zürich 1961). We assume that a large proportion of the internal migrants worked in these professions.

\section{Equations}

The anthropometric prediction equations found in the literature did not show satisfying results for our sample. Especially the weights were not precisely estimated. This is mainly because those equations were developed on different study populations. There is consensus in the literature that weight estimation formulas established for a specific population cannot be expected to work with the same precision for other populations (Sebo et al. 2015). Sample size, age of the study population, and measurement methods (e.g. measured, estimated, self-reported) are other factors that could explain why the application of the equations from the literature has led to imprecise results (Preedy 2012). An additional difference to other studies is that we used a historical sample. Most equations from the literature were developed in the last three decades. The equations from the literature worked better for the BMI estimation. With the exception of the Powell-Tuck and Hennessy (2003) equation, they were, however, still less accurate than our own. We also analyzed whether our equations work in a time of crisis. Our two main equations for weight and BMI provide very precise estimates during the Second World War (see Table 15 in the appendix).

We did not correct for age in our estimations. There are usually not enough conscripts in the age classes to allow a meaningful comparison. The sample size is large enough only for the years 1926 to 1929 for both 19- and 20-years old conscripts as well as for the year 1939 for 18- and 19-years old conscripts. We see only small differences in the anthropometric measures across age classes in those years (Table 13 in the appendix and Figure 7). There are only small differences in the regression estimates when we control for age (Table 14 in the appendix).

We over-estimate weights 1939, 1940, and 1941 as well as 1949, 1950, and 1951. Those two periods have values for height that are slightly above the long-term trend. Perhaps these taller conscripts did not in reality increase their weight exactly in proportion to their height. Regarding the weights before 1933 we see that the conscripts between 1925 and 1933 have height values falling slightly below the longterm trend. This might indicate a group with slightly shorter leg length, and hence greater weight than would be expected for their height. Overall, our weight estimates fit well with the lower weight average of $56.1 \mathrm{~kg}$ for Swiss conscripts in the conscription years 1875-1879 (Staub et al. 2016).

\section{Reconstruction}

All variables increased from 1904 to 1951 . Height showed a steady increase but it also stagnated during both world wars. As height is determined by the stature of previous generations and nutritional status during childhood, a smooth increasing curve was to be expected according to the literature (Hatton 2014; Baten and Blum 2012; Hatton and Bray 2010). For example, the dip in height around 1935 may reflect poor 
growth in the cohort that were in utero or infants during World War I. This may relate to adverse effects on maternal nutritional status of psychosocial stress or limited food rations.

In general, the standard of living increased (Figure 4). With the exception of the two world wars and the 1930s, real wages rose steadily. The real GDP p.c. followed this trend. In the 19th century, infant mortality was higher in the cities than in rural areas of Switzerland (Head-König 1998; Schoch, Staub, and Pfister 2012). Due to the rapid modernization of sewage and water supply systems, the modernization of the healthcare system, and the more rapid spread of hygienic and sanitary measures in urban centres, the situation reversed between 1870 and 1914 (Lorenzetti and Meffre 2005; Floris and Staub 2019; Floris, Staub, et al. 2019), with mortality decreasing more rapidly in the cities. Relative to other European countries, Switzerland was marked by an above average increase in GDP p. c. but only an average increase in real wages, life expectancy at birth, and average height (Floris, Höpflinger, et al. 2019).

Figure 4: Trends of real GDP per capita, average real wage, and infant mortality rates in Zurich. Panel A) District of Zurich real GDP data from Stohr (2016a; 2016b) and annual average real wages for Zurich and

Basel combined from Studer (2008) and Studer and Schuppli (2008). Panel B) Infant mortality 5-year average data from Statistisches Amt der Stadt Zürich (1951)

Working class families in Switzerland consumed mainly milk and dairy products, meat and fish, bread and cereal products, and potatoes (Tanner 1999, 151-55). According to Tanner, they drank considerably more milk than workers in Germany, Austria, and England and also ate relatively large amounts of bread. They consumed about the same amount of butter and cheese, but considerably less meat (Tanner 1999, 151-55). In 1912, Zurich workers spent about 40 percent of their income on food (Swiss Federal Statistical Office 2013a), whereas in 1953 the proportion was 30 percent. Milk, bread, potato, and meat consumption also dominated in Zurich (Table 4). The doubling of annual per capita milk consumption in Switzerland between 1875 and 1900 contributed to the increase in average height in the subsequent years (Staub and Rühli 2013). Other factors that impact the endocrine system and that contributed to the increase in height were the iodine-deficiency and rickets prophylaxis campaigns (Staub and Rühli 2013): Starting in the 1920s, school children received weekly iodine pills and iodized table salt was introduced; in the 1930s school children received vitamin D pills.

Table 4: Consumption per family of selected foodstuff in working-class households in the city of Zurich

There is a marked decrease in weight and BMI from 1916 to 1918. This reflects the worsening food condition during the First World War. The historical literature suggests that the food supply was stable in the first two years of the war but became limited thereafter (Rossfeld and Straumann 2008). The size of the decrease in average weight (-2.1 kg 1914 compared to 1918) indicates the worsening standard of living. Within two years of the war ending, a recovery to pre-war levels is visible. For BMI there was another 
decrease from 1930 to 1945 . During the 1930s, this trend was mostly due to the increase in height and stagnation of weight. Since BMI has squared height in the denominator, even small increases in height without corresponding increases in weight lower BMI significantly. The decrease in the 1940s is clearly related the Second World War, and particularly towards the end of the war, the average BMI of the conscripts seems to have suffered, reflecting the increasingly poor food situation (decline in imports and reduced rations). The decreased BMI at the beginning of the war, in 1940, could be related both to this cohort having received poorer nutrition early in life, along with the 1940s war-related change in diet due to the incipient rationing (reduced fat, meat and egg intake compared to pre-war nutrition) (Tanner 1999; Fleisch 1947). The decrease in weight and BMI in the Second World War was, however, less pronounced than in the First World War as the authorities were better prepared for a war. Plans for a possible war economy began being made in 1936 (Cottier 2014). In comparison to the First World War, soldiers received compensation for their loss of earnings, rationing was implemented from the beginning of the war, and possible trade-offs with other policy measures were mitigated and coordinated as well as possible (Kreis 2011; Jost 1998). A year after the Second World War, the pre-war level of weight and BMI was reached again.

The upper SEP group was heavier in 1904 than the other groups (Upper SEP: $62.62 \mathrm{~kg}, 95 \% \mathrm{Cl}: 61.30$ - 63.94kg; middle SEP: $57.55 \mathrm{~kg}, 95 \% \mathrm{Cl}$ : 56.84 - 58.27kg; lower SEP: $57.41 \mathrm{~kg}, 95 \% \mathrm{Cl}: 56.81$ - 58.01kg). In 1951, the difference was less than $2 \mathrm{~kg}$ (Upper SEP: 66.40kg, 95\% Cl: $65.57-67.23 \mathrm{~kg}$; middle SEP: 64.93kg, 95\% Cl: 64.47 - 65.40kg; lower SEP: $65.40 \mathrm{~kg}, 95 \% \mathrm{Cl}: 65.07-65.72 \mathrm{~kg}$ ). This difference cannot be observed for BMI. The main reason is that people in the upper SEP group were taller and thus also heavier. This could be due to the better food supply this group had. However, habitual physical activity and adaptation to the work environment, as well as differences in job profiles can bring out certain physical characteristics and could thus explain different SEP pattern (Schoch, Staub, and Pfister 2012). However, the lower and middle SEP groups also caught up with the upper SEP group in terms of height between 1904 and 1951, although the reduction of the difference between height levels is slower than for weight and the difference between the lower and middle group remains constant (Figure 5).

\section{Figure 5: SEP differentiated mean height 1904-1951}

We are aware that using a statistical measure of a population based only on the mean may not fully capture the true nature of changes in the population (Razak, Davey Smith, and Subramanian 2016). However, in the Swiss case, we know that the widening of the BMI distribution appeared after the 1950s and that BMI was almost symmetrically distributed in the 1870s and 1930s (Staub et al. 2018; 2016; 2010), which makes the problem less relevant to this paper. Furthermore, in this paper we cannot estimate what effect the Spanish flu may have had. Thus, we do not know if this negative health shock had a selection or a scarring effect on the later average height of the population (Deaton 2007). Another limitation of our approach is that body proportions can change. 
This study offers the first reconstruction and estimation of mean body weights and BMI values on a yearly basis for a representative sample of a historical population across the first half of the 20th century. Even though our estimation equations are based on a specific population, our approach could be replicated for other historical populations to obtain more information on how nutritional status changed over time. Not only can weight and BMI be predicted based on human remains, but also estimated relatively accurately in living individuals if other anthropometric measurements are available and the sample is large enough. Thus, we propose making greater use of these opportunities in historical anthropometry. 


\section{Bibliography}

Balode, Aija, Anda Stolarova, Anita Villerusa, Daina Zepa, Imants Kalnins, and Janis Vetra. 2015. "Estimation of Body Weight and Stature in Latvian Hospitalized Seniors." Papers on Anthropology XXIV (2): 2736.

Baten, Joerg, and Matthias Blum. 2012. "Growing Tall but Unequal: New Findings and New Background Evidence on Anthropometric Welfare in 156 Countries, 1810-1989." Economic History of Developing Regions 27 (sup1): S66-85. https://doi.org/10.1080/20780389.2012.657489.

Benítez Brito, Néstor, José Pablo Suárez Llanos, Manuel Fuentes Ferrer, Jose Gregorio Oliva García, Irina Delgado Brito, Francisca Pereyra-García Castro, Nieves Caracena Castellanos, Candelaria Xiomara Acevedo Rodríguez, and Enrique Palacio Abizanda. 2016. "Relationship between Mid-Upper Arm Circumference and Body Mass Index in Inpatients." Edited by Abelardo I Aguilera. PLOS ONE 11 (8): e0160480. https://doi.org/10.1371/journal.pone.0160480.

Carson, Scott Alan. 2016. "Body Mass Index through Time: Explanations, Evidence and Future Directions." In The Oxford Handbook of Economics and Human Biology, edited by John Komlos and Inas R. Kelly, 133-51. Oxford: Oxford University Press.

Cattermole, Giles N, Colin A Graham, and Timothy H Rainer. 2017. "Mid-Arm Circumference Can Be Used to Estimate Weight of Adult and Adolescent Patients." Emergency Medicine Journal 34 (4): 231-36. https://doi.org/10.1136/emermed-2015-205623.

Chittawatanarat, Kaweesak, Pruenglampoo, Trakunhoon, Ungpinitpong, and Patumanond. 2012. "Development of Gender- and Age Group-Specific Equations for Estimating Body Weight from Anthropometric Measurement in Thai Adults." International Journal of General Medicine, January, 65. https://doi.org/10.2147/IJGM.S27507.

Cottier, Maurice. 2014. Liberalismus oder Staatsintervention: Die Geschichte der Versorgungspolitik im Schweizer Bundesstaat. NZZ libro. Zürich: Verlag Neue Zürcher Zeitung.

Deaton, Angus. 2007. "Height, Health, and Development." Proceedings of the National Academy of Sciences 104 (33): 13232-37. https://doi.org/10.1073/pnas.0611500104.

Fleisch, Alfred. 1947. Ernährungsprobleme in Mangelzeiten: Die schweizerische Kriegsernährung 1939-1946. Basel: Schwabe \& Co.

Floris, Joël. 2016. "Körpergrösse, Body-Mass-Index und Geburtsgewichte: Lebensstandard und Anthropometrie in Zürich und Basel 1904-1951." Dissertation, Zürich: Universität Zürich.

Floris, Joël, François Höpflinger, Christian Stohr, Roman Studer, and Kaspar Staub. 2019. "Wealthier - Older - Taller: Measuring the Standard of Living in Switzerland since the 19th Century." Schweizerische Zeitschrift Für Geschichte 69 (2): 207-32.

Floris, Joël, and Kaspar Staub. 2019. "Water, Sanitation and Mortality in Swiss Towns in the Context of Urban Renewal in the Late Nineteenth Century." The History of the Family 24 (2): 249-76. https://doi.org/10.1080/1081602X.2019.1598460.

Floris, Joël, Kaspar Staub, Christian Stohr, and Ulrich Woitek. 2019. "Changes in mortality in Switzerland, 1880-1910." In Texte und Zahlen: der Platz quantitativer Ansätze in der Wirtschafts- und Sozialgeschichte, edited by Juan H Flores, Gisela Hürlimann, Luigi Lorenzetti, and Hans-Ulrich Schiedt.

Floris, Joël, Kaspar Staub, and Ulrich Woitek. 2016. "The Benefits of Intervention: Birth Weights in Basle 1912-1920." University of Zurich, Department of Economics, Working Paper 236.

Floud, Roderick, Robert W. Fogel, Bernard Harris, and Sok Chul Hong. 2011. The Changing Body: Health, Nutrition, and Human Development in the Western World since 1700. Cambridge: Cambridge University Press.

Hatton, Timothy J. 2014. "How Have Europeans Grown so Tall?" Oxford Economic Papers 66 (2): 349-72. https://doi.org/10.1093/oep/gpt030.

Hatton, Timothy J., and Bernice E. Bray. 2010. "Long Run Trends in the Heights of European Men, 19th20th Centuries." Economics \& Human Biology 8 (3): 405-13.

https://doi.org/10.1016/j.ehb.2010.03.001. 
Head-König, Anne-Lise. 1998. "La population de la Suisse." In Histoire des populations de l'Europe: La révolution démographique, 1750-1914, edited by Jean-Pierre Bardet and Jacques Dupâquier, 2:454-61. Paris: Fayard.

Jost, Hans Ulrich. 1998. Politik und Wirtschaft im Krieg: Die Schweiz 1938-1948. Zürich: Chronos.

Komlos, John, and Marek Brabec. 2010. "The Trend of Mean BMI Values of US Adults, Birth Cohorts 18821986 Indicates That the Obesity Epidemic Began Earlier than Hitherto Thought." American Journal of Human Biology 22 (5): 631-38. https://doi.org/10.1002/ajhb.21055.

Komlos, John, and Scott Alan Carson. 2017. "The Bmi Values of the Lower Classes Likely during the Great Depression." Economics and Human Biology 26: 137-43.

Kreis, Georg. 2011. Die Schweiz im Zweiten Weltkrieg. Aktualisierte Neuausgabe, 1. Auflage. HaymonTaschenbuch 68. Innsbruck: Haymon-Verlag.

Kurz, Hans Rudolf. 1985. Geschichte der Schweizer Armee. Frauenfeld: Huber.

Lorenzetti, Luigi, and Véronique Meffre. 2005. "La transition sanitaire dans les alpes suisses: Les aspects démographiques du retard (1880-1920)." Histoire des Alpes 10: 233-50.

Melo Ferreira, Ana Paula Ferreira, Raquel Kuerten de Salles, Francilene Gracieli Kunradi Viera, and Marilyn Gonçalves Ferreira. 2014. "Methods for Estimation Body Weight and Height in Hospitalized Adults: A Comparative Analysis." Revista Brasileira de Cineantropometria \& Desempenho Humano 16 (4).

Ostchega, Yechiam, Ronald J. Prineas, Charles Dillon, Margaret McDowell, and Margaret Carroll. 2004. "Estimating Equations and Tables for Adult Mid-Arm Circumference Based on Measured Height and Weight: Data from the Third National Health and Nutrition Examination Survey (NHANES III) and NHANES 1999-2000:" Blood Pressure Monitoring 9 (3): 123-31. https://doi.org/10.1097/01.mbp.0000132427.32886.a9.

Panczak, Radoslaw, Ulrich Woitek, Frank J. Rühli, and Kaspar Staub. 2013. "Regionale und sozioökonomische Unterschiede im Body Mass Index von Schweizer Stellungspflichtigen 2004-2012." Studie im Auftrag des Bundesamtes für Gesundheit (BAG). Zürich: Zentrum für Evolutionäre Medizin der Universität Zürich.

Powell-Tuck, J, and Enid M. Hennessy. 2003. "A Comparison of Mid Upper Arm Circumference, Body Mass Index and Weight Loss as Indices of Undernutrition in Acutely Hospitalized Patients." Clinical Nutrition 22 (3): 307-12. https://doi.org/10.1016/S0261-5614(03)00009-8.

Preedy, Victor R., ed. 2012. Handbook of Anthropometry: Physical Measures of Human Form in Health and Disease. New York, NY: Springer New York. https://doi.org/10.1007/978-1-4419-1788-1.

Razak, Fahad, George Davey Smith, and Sv Subramanian. 2016. "The Idea of Uniform Change: Is It Time to Revisit a Central Tenet of Rose's 'Strategy of Preventive Medicine'?" The American Journal of Clinical Nutrition 104 (6): 1497-1507. https://doi.org/10.3945/ajcn.115.127357.

Rosenberg, Emily S., ed. 2012. A World Connecting 1870-1945. Vol. 5. A History of the World. Cambridge MA: Harvard UP.

Rossfeld, Roman, and Tobias Straumann, eds. 2008. Der vergessene Wirtschaftskrieg: Schweizer Unternehmen im Ersten Weltkrieg. Zürich: Chronos-Verl.

Ruff, Christopher B. 2018a. "Introduction." In Skeletal Variation and Adaptation in Europeans: Upper Paleolithic to the Twentieth Century, edited by Christopher B. Ruff, 1-13. Hoboken, NJ, USA: John Wiley \& Sons, Inc. https://doi.org/10.1002/9781118628430.ch1.

- - , ed. 2018b. Skeletal Variation and Adaptation in Europeans: Upper Paleolithic to the Twentieth Century. Hoboken, NJ, USA: John Wiley \& Sons, Inc. https://doi.org/10.1002/9781118628430.

Schoch, Tobias, Kaspar Staub, and Christian Pfister. 2012. "Social Inequality and the Biological Standard of Living: An Anthropometric Analysis of Swiss Conscription Data, 1875-1950." Economics and Human Biology 10 (2): 154-73.

Schüren, Reinhard. 1989. Soziale Mobilität: Muster, Veränderung und Bedingungen im 19. und 20. Jahrhundert. St. Katharina: Scripta Marcaturae Verlag.

Schweizerische Armee. 1887. Instruktion über die sanitarische Beurtheilung der Wehrpflichtigen (I.B.W. 1887). Bern.

-- . 1932. Instruktion über die sanitarische Beurteilung der Wehrpflichtigen (I.B.W. 1932). Bern.

- - . 1941. Instruktion über die sanitarische Beurteilung der Wehrpflichtigen (I.B.W. 1941). Bern.

-- - 1952. Instruktion über die sanitarische Beurteilung der Wehrpflichtigen (I.B.W. 1952). Bern. 
Sebo, P, D Haller, A Pechère-Bertschi, P Bovier, and F Herrmann. 2015. "Accuracy of Doctors' Anthropometric Measurements in General Practice." Swiss Medical Weekly, February. https://doi.org/10.4414/smw.2015.14115.

Statistisches Amt der Stadt Zürich. 1929. Statistisches Jahrbuch der Stadt Zürich 1924. Vol. 20. Zürich: Buchdruckerei Berichthaus.

---. 1951. Statistisches Jahrbuch der Stadt Zürich 1950. Vol. 46. Zürich: Buchdruckerei Berichthaus.

- - . 1961. Statistisches Jahrbuch der Stadt Zürich 1960. Vol. 56. Zürich: Buchdruckerei Berichthaus.

Staub, Kaspar. 2016. "Der vermessene menschliche Körper als Spiegel der Ernährungs- und Gesundheitsverhältnisse am Ende des Ersten Weltkrieges." In "Woche für Woche neue Preisaufschläge": Nahrungsmittel-, Energie- und Ressourcenkonflikte in der Schweiz des Ersten Weltkrieges, edited by Daniel Krämer, Christian Pfister, and Daniel Marc Segesser, 285-305. Wirtschafts-, Sozial- und Umweltgeschichte (WSU), Band 6. Basel: Schwabe Verlag.

Staub, Kaspar, Nicole Bender, Joël Floris, Christian Pfister, and Frank J. Rühli. 2016. "From Undernutrition to Overnutrition: The Evolution of Overweight and Obesity among Young Men in Switzerland since the 19th Century." Obesity Facts 9 (4): 259-72.

Staub, Kaspar, Maciej Henneberg, Francesco M Galassi, Patrick Eppenberger, Martin Haeusler, Irina Morozova, Frank J Rühli, and Nicole Bender. 2018. "Increasing Variability of Body Mass and Health Correlates in Swiss Conscripts, a Possible Role of Relaxed Natural Selection?" Evolution, Medicine, and Public Health 2018 (1): 116-26. https://doi.org/10.1093/emph/eoy012.

Staub, Kaspar, and Frank J. Rühli. 2013. "'From Growth in Height to Growth in Breadth': The Changing Body Shape of Swiss Conscripts since the Late 19th Century and Possible Endocrine Explanations." General and Comparative Endocrinology 188: 9-15. https://doi.org/10.1016/j.ygcen.2013.03.028.

Staub, Kaspar, Frank J. Rühli, Ulrich Woitek, and Christian Pfister. 2010. "BMI Distributional/Social Stratification in Swiss Conscripts from 1875 to Present." European Journal of Clinical Nutrition 64 (4): 335-40.

Steckel, Richard H. 2009. "Heights and Human Welfare: Recent Developments and New Directions." Explorations in Economic History 46 (1): 1-23. https://doi.org/10.1016/j.eeh.2008.12.001.

Steckel, Richard H., and Jerome C. Rose, eds. 2002. The Backbone of History: Health and Nutrition in the Western Hemisphere. 1st ed. Cambridge University Press. https://doi.org/10.1017/СBO9780511549953.

Stohr, Christian. 2016a. "Multiple Core Regions: Regional Inequality in Switzerland, 1851-2008." London School of Economics, Economic HIstory Working Paper Series 250.

-- - 2016b. "Trading Gains: New Estimates of Swiss GDP, 1851-2008." London School of Economics, Economic HIstory Working Paper Series 245.

Studer, Roman. 2008. "'When Did the Swiss Get so Rich?' Comparing Living Standards in Switzerland and Europe, 1800-1913." The Journal of European Economic History 2: 405-51.

Studer, Roman, and Pascal Schuppli. 2008. "Deflating Swiss Prices over the Past Five Centuries." Historical Methods: A Journal of Quantitative and Interdisciplinary History 41 (3): 137-56. https://doi.org/10.3200/HMTS.41.3.137-156.

Sultana, Tania, Md. Nazmul Karim, Tahmeed Ahmed, and Md. Iqbal Hossain. 2015. "Assessment of under Nutrition of Bangladeshi Adults Using Anthropometry: Can Body Mass Index Be Replaced by MidUpper-Arm-Circumference?" Edited by Maciej Buchowski. PLOS ONE 10 (4): e0121456. https://doi.org/10.1371/journal.pone.0121456.

Swiss Federal Statistical Office, ed. 2013a. "Haushaltungsrechnungen von Arbeiterfamilien: Einnahmen, Ausgaben und Struktur der Ausgaben in den Städten Zürich, Basel und Bern 1912-1973 (ausgewählte Erhebungen)." Table: OFS number 20.2.3.3.

- - , ed. 2013b. "Haushaltungsrechnungen von Arbeiterfamilien: Struktur der Nahrungsmittelausgaben in der Stadt Zürich 1912-1973 (ausgewählte Erhebungen)." Table: OFS number 20.3.3.

Tang, Alice M., Kimberly Dong, Megan Deitchler, Mei Chung, Zeina Maalouf-Manasseh, Alison Tumilowicz, and Christine Wanke. 2013. Use of Cutoffs for Mid-Upper Arm Circumference (MUAC) as an Indicator or Predictor of Nutritional and Health-Related Outcomes in Adolescents and Adults: A Systematic Review. Washington: FANTA.

Tanner, Jakob. 1999. Fabrikmahlzeit: Ernährungswissenschaft, Industriearbeit und Volksernährung in der Schweiz, 1890-1950. Zürich: Chronos. 
Wells, Jonathan CK, Jane E Williams, Dalia Haroun, Mary S Fewtrell, Antonio Colantuoni, and Mario Siervo. 2009. "Aggregate Predictions Improve Accuracy When Calculating Metabolic Variables Used to Guide Treatment." The American Journal of Clinical Nutrition 89 (2): 491-99. https://doi.org/10.3945/ajcn.2008.26629.

WHO Expert Committee, ed. 1995. Physical Status: The Use and Interpretation of Anthropometry: Report of a WHO Expert Committee. WHO Technical Report Series 854. Geneva: World Health Organization.

Willett, Walter, and Frank Hu. 2012. "Anthropometric Measures and Body Composition." In Nutritional Epidemiology, edited by Walter Willett, 3rd ed. Vol. 40. Monographs in Epidemiology and Biostatistics. Oxford: Oxford University Press. https://doi.org/10.1093/acprof:oso/9780199754038.001.0001. 
Table 1: Equations from the Literature

Benítez Brito et al. 2016: BMI

Aim Cut-off point of mid upper arm circumference (MUAC) for $\mathrm{BMI}<18.5$

Equation $\quad \mathrm{BMI}=-0.042+0.873 \times \operatorname{MUAC}(\mathrm{cm})$

Participants $n=1373$, hospitalized adults

Sultana et al. 2015: BMI

Aim Cut-off point of mid upper arm circumference (MUAC) for BMI $<18.5$

Equation $\quad \operatorname{MUAC}(\mathrm{cm})=10.481+0.718 \times \mathrm{BMI}$

Participants $n=650$, adults

Powell-Tuck and Hennessy 2003: BMI (2 equations)

Aim Comparison of mid upper arm circumference (MUAC), BMI, weight loss

Equation $\quad B M I=1.01 \times \operatorname{MUAC}(\mathrm{cm})-4.7$

Equation $\quad B M I=1.02 \times M U A C+0.03 \times$ age -6.7

Participants $n=603$, hospitalized adults

\section{Cattermole et al. 2017: Weight}

Aim Mid upper arm circumference (MUAC) for weight estimation

Equation Weight $(\mathrm{kg})=3.8484 \times \operatorname{MUAC}(\mathrm{cm})-46.8585$

Participants $n=17,520$, NHANES (2011-2012 and 2009-2010), 11-80 years

\section{Chittawatanarat et al. 2012: Weight}

Aim Chest circumference $(\mathrm{ChC})$ and height $(\mathrm{Ht})$ for weight $(\mathrm{Wt})$ estimation

Equation $\quad W t=1.12 \times \mathrm{ChC}(\mathrm{cm})+0.39 \times \mathrm{Ht}(\mathrm{cm})-100.4$

Participants $n=2000$, adults

Ostchega et al. 2004: Weight

Aim Weight (Wt), height $(\mathrm{Ht})$ and age for mid upper arm circumference (MUAC) estimation

Equation $\quad \operatorname{MUAC}(\mathrm{cm})=31.76749+0.22626 \times \mathrm{Wt}(\mathrm{kg})-0.10109 \times \mathrm{Ht}(\mathrm{cm})+0.05092 \times$ age (years) $0.00081813 \times$ age $^{\wedge} 2$

Participants Participants: $n=14,690$, adults, NHANES III and 1999-2000 
Table 2: Own equation estimation accuracy weight (kg)

\begin{tabular}{|c|c|c|}
\hline & $\begin{array}{c}\text { Test dataset } \\
1933-1938\end{array}$ & $\begin{array}{c}\text { Validation dataset } \\
1947-1951 \\
\end{array}$ \\
\hline \multicolumn{3}{|c|}{ Average of based on 3 simple regression equations (WChest, WArm, WHeight) } \\
\hline Actual mean & 63.25 & 63.58 \\
\hline Predicted mean & 63.27 & 64.27 \\
\hline Difference & -0.02 & -0.69 \\
\hline No. of values in a 10 percent range (in \%) & 86.21 & 84.92 \\
\hline \multicolumn{3}{|c|}{ Weight $=$ Intercept + Chest + Arm + Height $($ WCAH $)$} \\
\hline Actual mean & 63.25 & 63.58 \\
\hline Predicted mean & 63.25 & 64.85 \\
\hline Difference & -0.01 & -1.27 \\
\hline No. of values in a 10 percent range (in \%) & 94.59 & 91.84 \\
\hline \multicolumn{3}{|l|}{ Weight $=$ Intercept + Chest + Arm (WCA) } \\
\hline Actual mean & 63.25 & 63.58 \\
\hline Predicted mean & 63.29 & 64.40 \\
\hline Difference & -0.04 & -0.82 \\
\hline No. of values in a 10 percent range (in \%) & 85.39 & 84.43 \\
\hline \multicolumn{3}{|l|}{ Weight $=$ Intercept + Chest + Height $(\mathrm{WCH})$} \\
\hline Actual mean & 63.25 & 63.58 \\
\hline Predicted mean & 63.36 & 65.36 \\
\hline Difference & -0.11 & -1.78 \\
\hline No. of values in a 10 percent range (in \%) & 85.62 & 78.29 \\
\hline \multicolumn{3}{|l|}{ Weight $=$ Intercept + Arm + Height $($ WAH) } \\
\hline Actual mean & 63.25 & 63.58 \\
\hline Predicted mean & 63.19 & 64.41 \\
\hline Difference & 0.06 & -0.83 \\
\hline No. of values in a 10 percent range (in \%) & 91.67 & 90.04 \\
\hline
\end{tabular}


Table 3: Own equation estimation accuracy BMI $(\mathrm{kg} / \mathrm{m} 2)$

\begin{tabular}{|c|c|c|}
\hline & $\begin{array}{c}\text { Test dataset } \\
1933-1938\end{array}$ & $\begin{array}{c}\text { Validation dataset } \\
1947-1951\end{array}$ \\
\hline \multicolumn{3}{|c|}{ Average of based on 3 simple regression equations (BMIChest, BMIArm, BMIHeight) } \\
\hline Actual mean & 21.49 & 21.14 \\
\hline Predicted mean & 21.50 & 21.62 \\
\hline Difference & -0.01 & -0.48 \\
\hline No. of values in a 10 percent range (in \%) & 85.72 & 79.50 \\
\hline \multicolumn{3}{|c|}{ BMI $=$ Intercept + Chest + Arm + Height (BMICAH) } \\
\hline Actual mean & 21.49 & 21.14 \\
\hline Predicted mean & 21.49 & 21.56 \\
\hline Difference & -0.00 & -0.42 \\
\hline No. of values in a 10 percent range (in \%) & 94.79 & 92.06 \\
\hline \multicolumn{3}{|l|}{ BMI = Intercept + Chest + Arm (BMICA) } \\
\hline Actual mean & 21.49 & 21.14 \\
\hline Predicted mean & 21.49 & 21.66 \\
\hline Difference & 0.01 & -0.52 \\
\hline No. of values in a 10 percent range (in \%) & 91.53 & 86.46 \\
\hline \multicolumn{3}{|l|}{ BMI = Intercept + Chest + Height $(\mathrm{BMICH})$} \\
\hline Actual mean & 21.49 & 21.14 \\
\hline Predicted mean & 21.53 & 21.73 \\
\hline Difference & -0.04 & -0.59 \\
\hline No. of values in a 10 percent range (in \%) & 85.62 & 78.06 \\
\hline \multicolumn{3}{|l|}{ BMI = Intercept + Arm + Height (BMIAH) } \\
\hline Actual mean & 21.49 & 21.14 \\
\hline Predicted mean & 21.47 & 21.41 \\
\hline Difference & 0.02 & -0.27 \\
\hline No. of values in a 10 percent range (in \%) & 91.86 & 90.06 \\
\hline
\end{tabular}


Table 4: Consumption per family of selected foodstuff in working-class households in the city of Zurich

\begin{tabular}{|c|c|c|c|c|c|c|c|c|c|}
\hline Year & $\begin{array}{c}\text { Bread } \\
(\mathrm{kg})\end{array}$ & $\begin{array}{l}\text { Flour } \\
\text { (kg) }\end{array}$ & $\begin{array}{c}\text { Pasta } \\
\text { (kg) }\end{array}$ & $\begin{array}{l}\text { Potatoes } \\
\text { (kg) }\end{array}$ & $\begin{array}{c}\text { Vegetables } \\
\text { and legumes } \\
\text { (kg) }\end{array}$ & $\begin{array}{c}\text { Fruits } \\
\text { and nuts } \\
\text { (kg) }\end{array}$ & $\begin{array}{l}\text { Milk and } \\
\text { cream (I) }\end{array}$ & $\begin{array}{l}\text { Butter and } \\
\text { cheese (kg) }\end{array}$ & $\begin{array}{c}\text { Meat } \\
(\mathrm{kg})\end{array}$ \\
\hline 1912 & 336 & 24 & 26 & 160 & & 150 & 910 & 28 & 108 \\
\hline 1919 & 310 & 28 & 29 & 235 & & 304 & 965 & 29 & 76 \\
\hline 1920 & 337 & 28 & 30 & 208 & 135 & 269 & 967 & 45 & 78 \\
\hline 1921 & 359 & 30 & 29 & 236 & 120 & 202 & 1060 & 39 & 85 \\
\hline 1922 & 340 & 32 & 29 & 213 & & 311 & 1120 & 44 & 110 \\
\hline 1923 & 423 & 33 & 35 & 230 & & 215 & 1132 & 42 & 111 \\
\hline $1936 / 37$ & 242 & 25 & 26 & 177 & 163 & 233 & 752 & 40 & 96 \\
\hline 1943 & 314 & 19 & 16 & 421 & 200 & 349 & 793 & 42 & 77 \\
\hline 1946 & 270 & 24 & 31 & 435 & 167 & 374 & 769 & 37 & 75 \\
\hline 1949 & 238 & 24 & 30 & 262 & 164 & 321 & 818 & 42 & 87 \\
\hline 1953 & 252 & 24 & 34 & 203 & 180 & 335 & 769 & 45 & 88 \\
\hline
\end{tabular}

Source: (Swiss Federal Statistical Office 2013b) 
Figures

Figure 1: Mean changes in anthropometric measures among conscripts 1904 to 1951 (measured values)
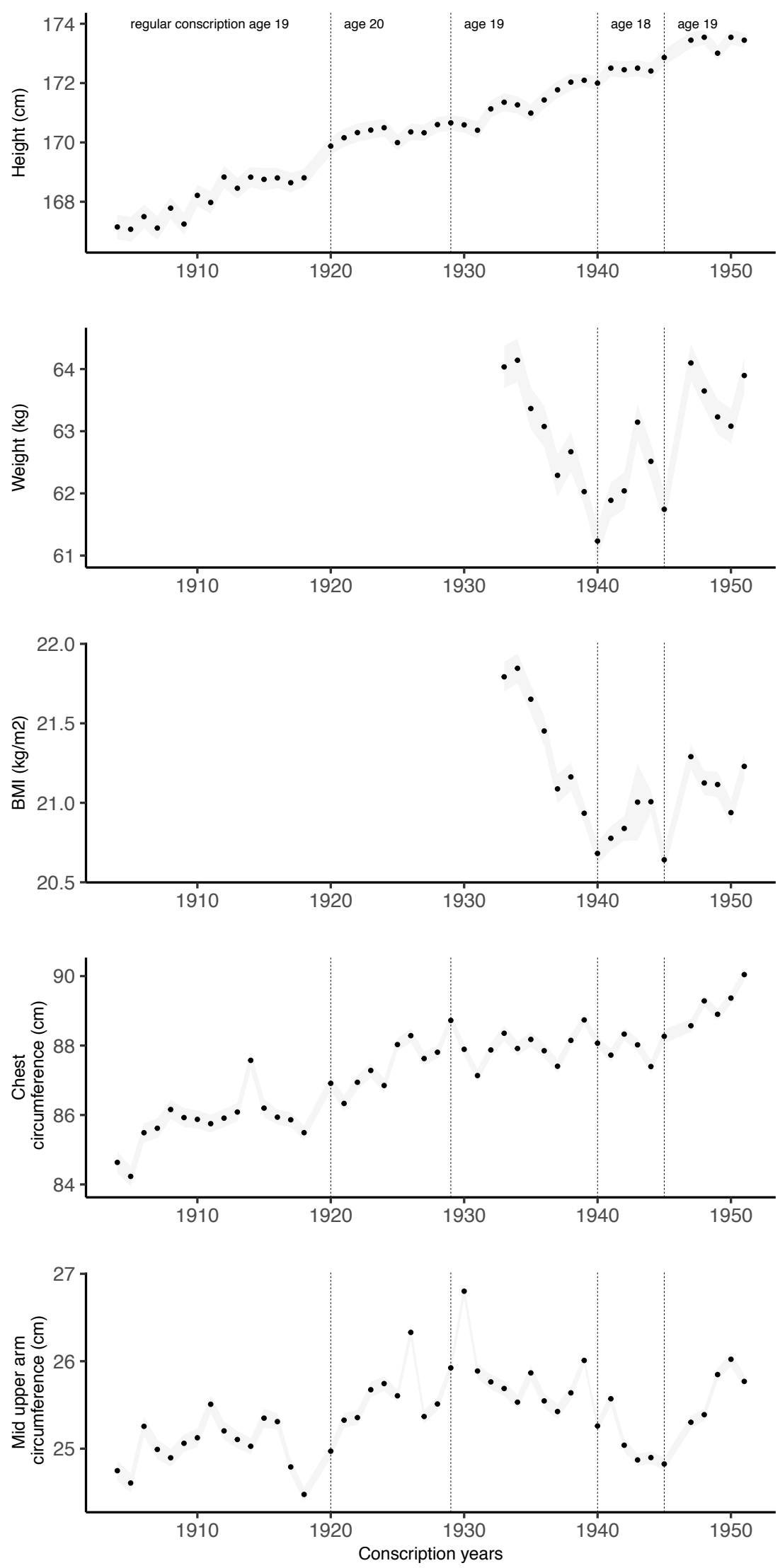
Figure 2: Estimated mean weight and SEP differentiated mean weight 1904-1951 (WCAH equation)
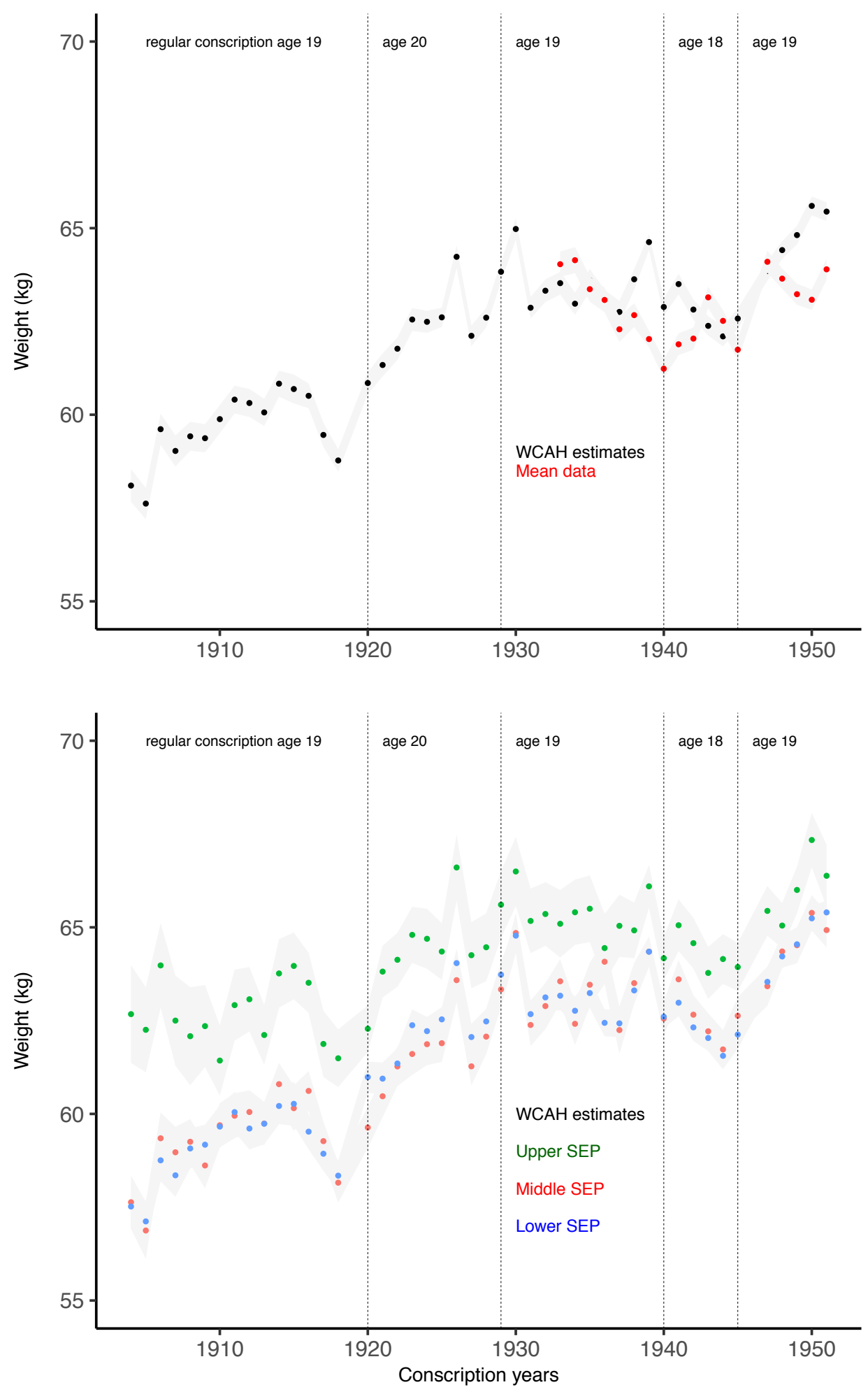
Figure 3: Estimated mean BMI and SEP differentiated estimated mean BMI 1904-1951 (BMICAH equation)
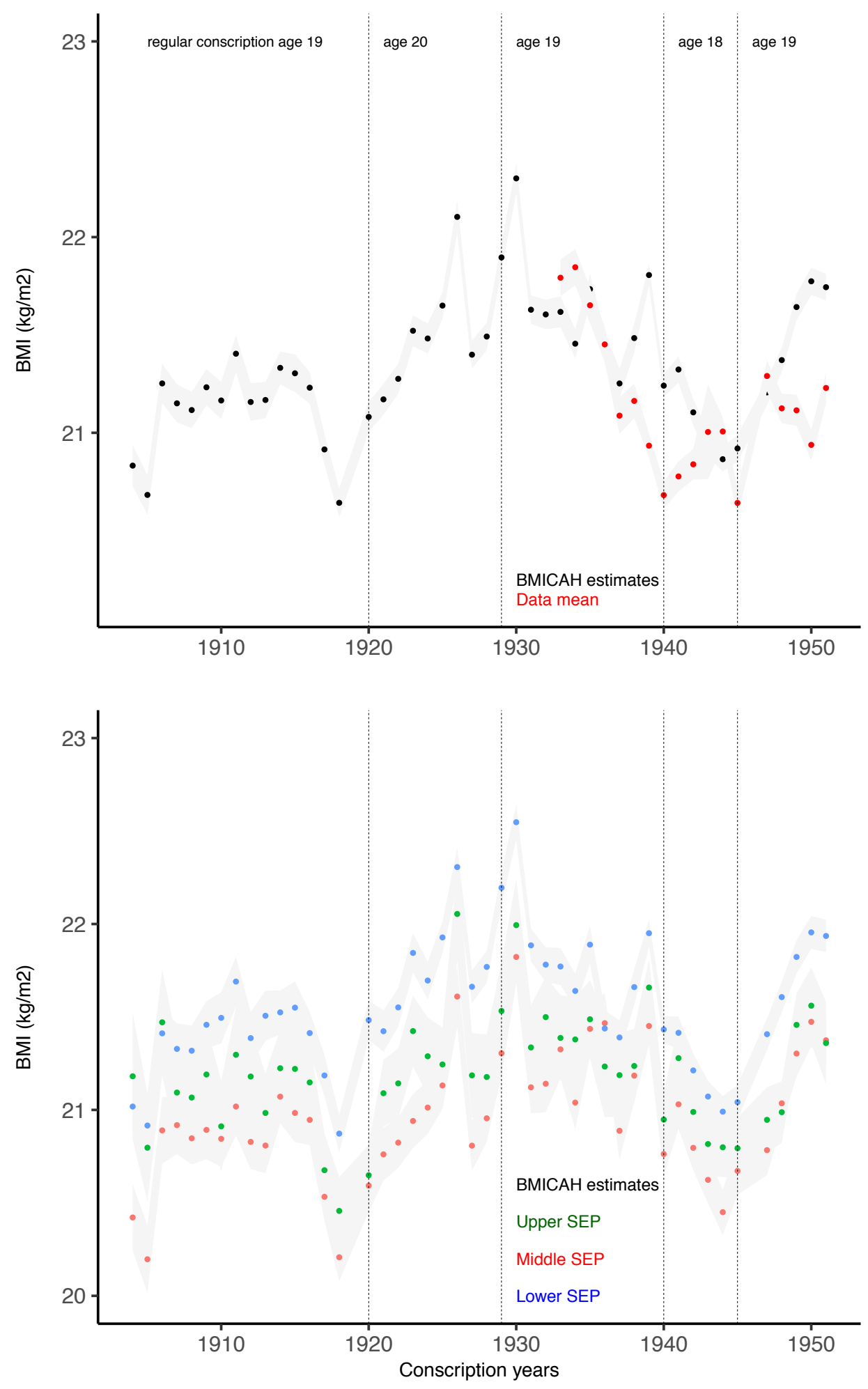
Figure 4: Trends of real GDP per capita, average real wage, and infant mortality rates in Zurich. Panel A) District of Zurich real GDP data from Stohr (2016a; 2016b) and annual average real wages for Zurich and Basel combined from Studer (2008) and Studer and Schuppli (2008). Panel B) Infant mortality 5-year average data from Statistisches Amt der Stadt Zürich (1951)
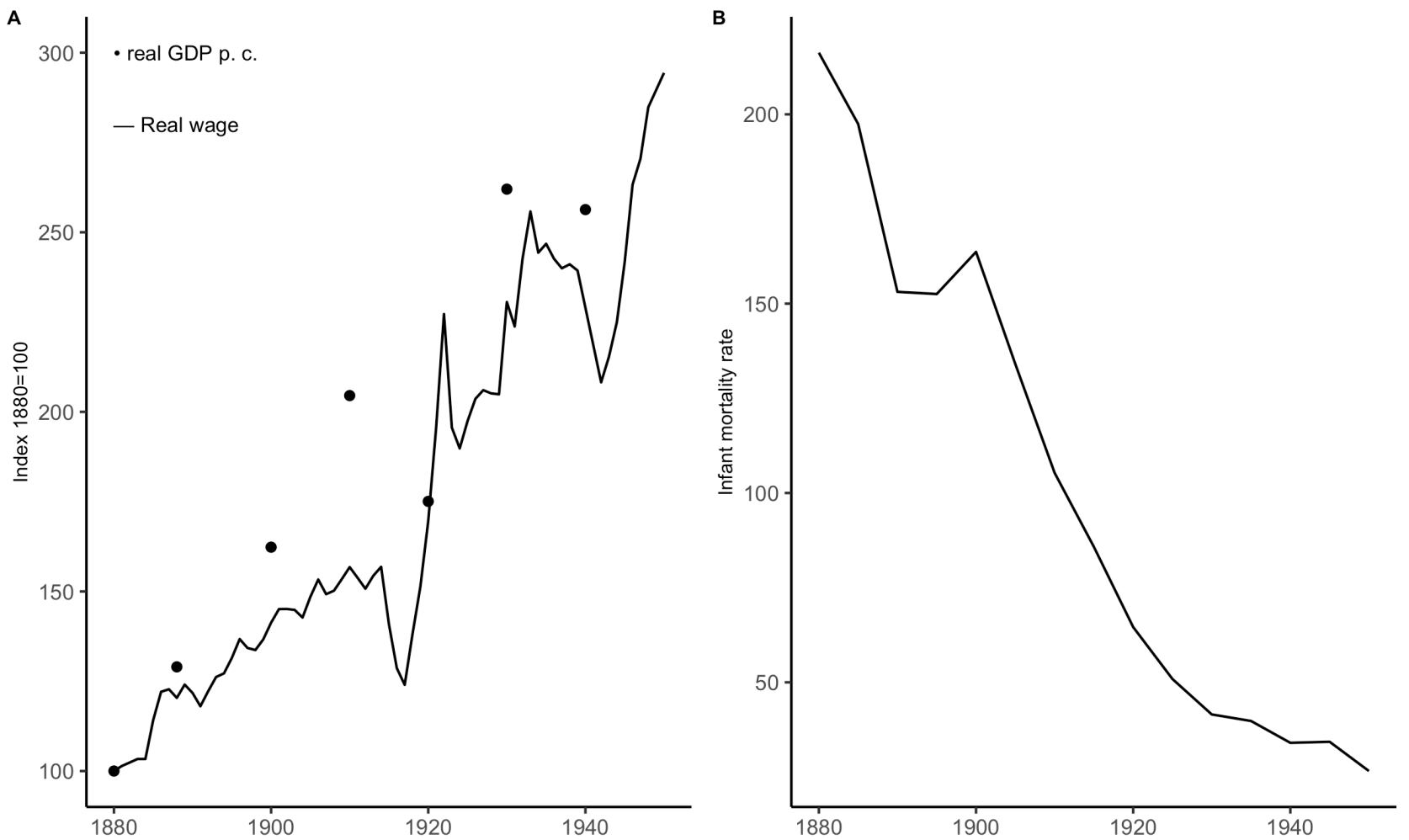

Figure 5: SEP differentiated mean height 1904-1951

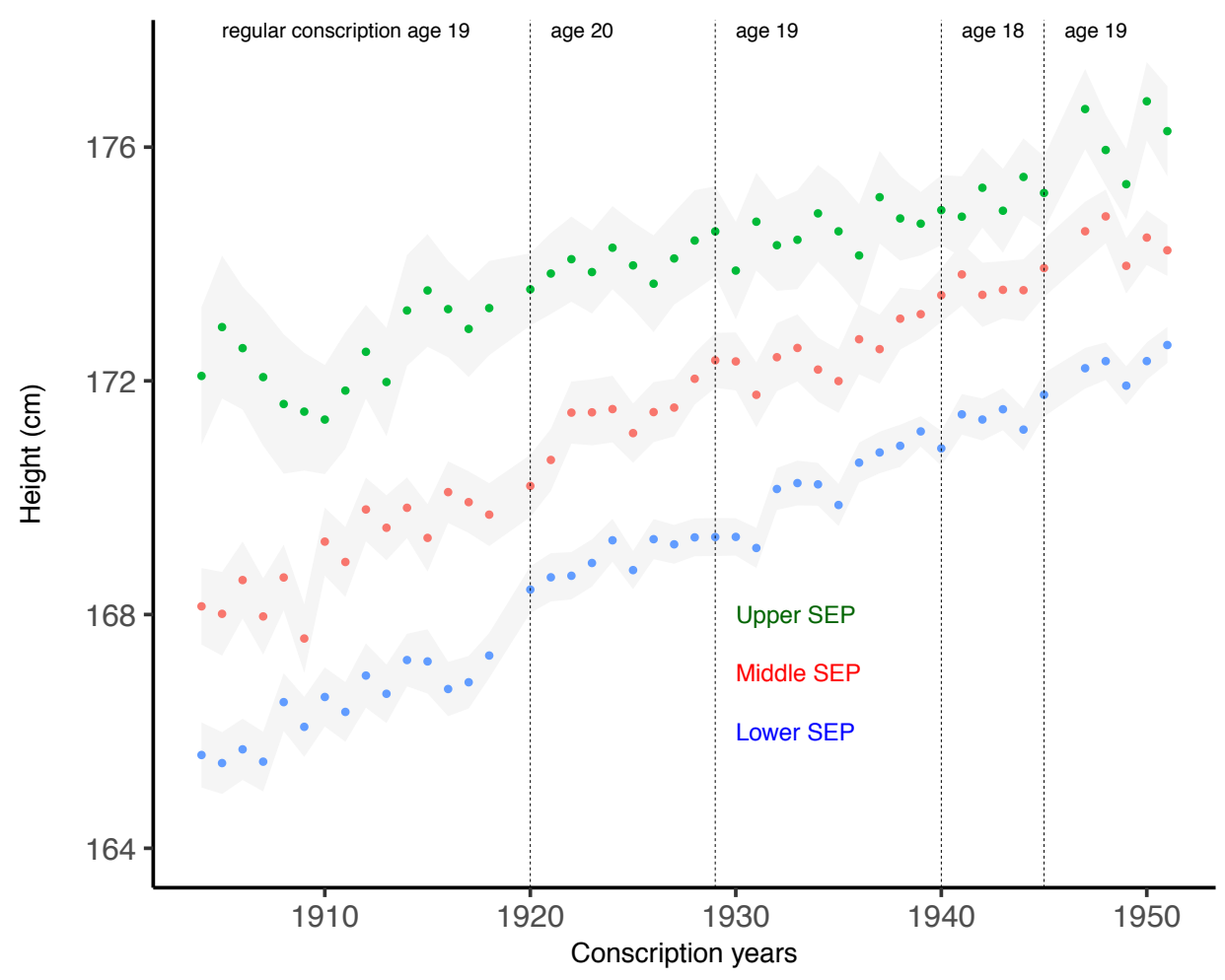


Figure 6: Shares of the occupational stratification groups over time

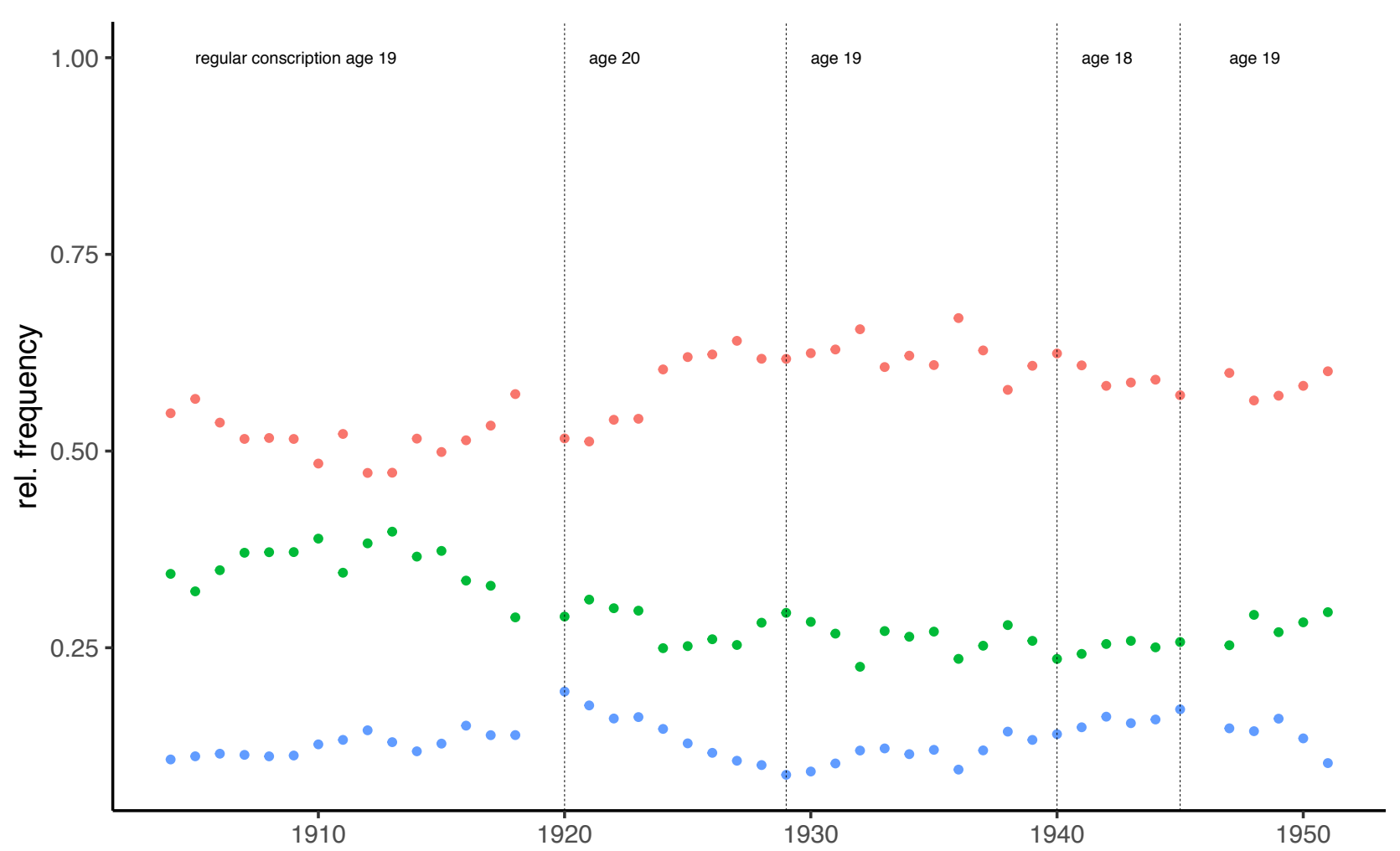

- lower SEP - middle SEP - upper SEP 
Table 5: Overall age distribution at conscription 1904-1951

\begin{tabular}{ccc}
\hline Age class & $\mathbf{N}$ & $\mathbf{\%}$ \\
\hline$<19$ & 14524 & 16.4 \\
{$[19-20)$} & 49978 & 56.3 \\
{$[20-21)$} & 19736 & 22.2 \\
21 & 4554 & 5.1 \\
\hline
\end{tabular}

Table 6: Summary statistics train and test dataset (height $\mathrm{cm}$ )

\begin{tabular}{|c|c|c|c|c|c|c|c|c|c|}
\hline \multicolumn{10}{|c|}{ Training dataset 1933-1938 } \\
\hline & $\mathbf{N}$ & Mean & SD & Min & $25 \%$ & Median & $75 \%$ & Max & IQR \\
\hline Farmer & 70 & 170.7 & 6.9 & 156.5 & 167.0 & 170.0 & 174.4 & 188.5 & 7.4 \\
\hline Low SEP & 3414 & 170.5 & 6.1 & 148.0 & 166.5 & 170.5 & 174.5 & 201.0 & 8.0 \\
\hline Middle SEP & 1448 & 172.4 & 6.2 & 142.0 & 168.0 & 172.5 & 176.5 & 197.0 & 8.5 \\
\hline Upper SEP & 655 & 174.7 & 6.1 & 157.0 & 170.5 & 174.5 & 179.0 & 193.5 & 8.5 \\
\hline NA & 22 & 173.4 & 8.3 & 154.5 & 169.1 & 173.8 & 179.5 & 186.0 & 10.4 \\
\hline \multicolumn{10}{|c|}{ Test dataset 1933-1938 } \\
\hline & $\mathbf{N}$ & Mean & SD & Min & $25 \%$ & Median & $75 \%$ & Max & IQR \\
\hline Farmer & 73 & 171.1 & 7.5 & 155.0 & 166.0 & 171.0 & 176.0 & 190.0 & 10.0 \\
\hline Low SEP & 3408 & 170.4 & 6.3 & 143.0 & 166.5 & 170.5 & 175.0 & 194.0 & 8.5 \\
\hline Middle SEP & 1443 & 172.6 & 6.3 & 129.0 & 169.0 & 172.5 & 177.0 & 195.0 & 8.0 \\
\hline Upper SEP & 660 & 174.6 & 6.0 & 157.0 & 170.5 & 174.5 & 178.5 & 197.0 & 8.0 \\
\hline NA & 30 & 169.2 & 7.3 & 152.0 & 165.1 & 171.5 & 173.9 & 182.0 & 8.8 \\
\hline
\end{tabular}


Table 7: Estimated regression equations weight

Training dataset 1933-1938

Name: WHeight

Intercept

Height

R2

Name: WChest

Intercept

Chest circumference

R2

Name: WHeight

Intercept

Upper arm circumference

R2

Name WCAH

Intercept

Chest circumference

Upper arm circumference

Height

adj. R2

Name: WCA

Intercept

Chest circumference

Upper arm circumference

adj. R2

Name: WCH

Intercept

Chest circumference

Height

adj. R2

Name: WAH

Intercept

Upper arm circumference

Height

adj. $\mathbf{R} 2$

$\begin{array}{cccc}\text { Estimate } & \text { SE } & \text { t value } & p \text { value } \\ -49.52 & 2.16 & -22.94 & <0.0001 \\ 0.66 & 0.01 & 52.27 & <0.0001 \\ 0.33 & & & \end{array}$

$\begin{array}{cccc}-44.95 & 1.27 & -36.05 & <0.0001 \\ 1.24 & 0.01 & 85.80 & <0.0001 \\ 0.57 & & & \end{array}$

$\begin{array}{llll}-9.22 & 0.93 & -9.88 & <0.0001 \\ 2.83 & 0.04 & 77.88 & <0.0001 \\ 0.52 & & & \end{array}$

$\begin{array}{cccc}-102.53 & 1.32 & -77.43 & <0.0001 \\ 0.50 & 0.01 & 34.39 & <0.0001 \\ 1.81 & 0.03 & 55.84 & <0.0001 \\ 0.44 & 0.01 & 55.98 & <0.0001 \\ 0.78 & & & \end{array}$

$\begin{array}{cccc}-48.43 & 1.13 & -42.8 & <0.0001 \\ 0.81 & 0.02 & 48.10 & <0.0001 \\ 1.57 & 0.04 & 39.03 & <0.0001 \\ 0.66 & & & \end{array}$

$\begin{array}{cccc}-92.48 & 1.64 & -56.46 & <0.0001 \\ 1.03 & 0.01 & 74.15 & <0.0001 \\ 0.38 & 0.01 & 39.19 & <0.0001 \\ 0.66 & & & \end{array}$

Rounded to two decimal places 
Table 8: Estimated regression equations BMI

Training dataset 1933-1938

$\begin{array}{lcccc}\text { Name: BMIHeight } & \text { Estimate } & \text { SE } & \text { t value } & \text { p value } \\ \text { Intercept } & 26.00 & 0.73 & 35.64 & <0.0001 \\ \text { Height } & -0.03 & 0.00 & -6.18 & <0.0001 \\ \text { R2 } & 0.01 & & & \end{array}$

Name: BMIChest

Intercept

Chest circumference

$\begin{array}{llll}-3.33 & 0.42 & -7.85 & <0.0001 \\ 0.28 & 0.00 & 58.62 & <0.0001 \\ 0.38 & & & \end{array}$

Name: BMIArm

Intercept

$\begin{array}{cccc}0.38 & 0.24 & 1.55 & 0.12 \\ 0.82 & 0.01 & 86.60 & <0.0001\end{array}$

R2

0.57

Name: BMICAH

Intercept

$\begin{array}{llll}8.04 & 0.44 & 18.09 & <.0001\end{array}$

Chest circumference

$\begin{array}{llll}0.17 & 0.00 & 34.70 & <0.0001\end{array}$

Upper arm circumference

$\begin{array}{llll}0.61 & 0.01 \quad 56.46 & <.0001\end{array}$

Height

$\begin{array}{llll}-0.10 & 0.00 & -38.33<0.0001\end{array}$

adj. $\mathbf{R} 2$

0.68

Name: BMICA

Intercept

$\begin{array}{llll}-4.39 & 0.34 & -12.86 & <0.0001 \\ 0.10 & 0.01 & 19.39 & <0.0001 \\ 0.67 & 0.01 & 55.30 & <0.0001 \\ 0.60 & & & \end{array}$

Name: BMICH

Intercept

Chest circumference

$\begin{array}{cccc}11.44 & 0.55 & 20.74 & <0.0001 \\ 0.35 & 0.00 & 74.60 & <0.0001 \\ -0.12 & 0.00 & -36.94 & <0.0001 \\ 0.50 & & & \end{array}$

Name: BMIAH

\begin{tabular}{lcccc} 
Intercept & 10.80 & 0.48 & 22.40 & $<0.0001$ \\
Upper arm circumference & 0.86 & 0.01 & 93.94 & $<0.0001$ \\
Height & -0.07 & 0.00 & -24.67 & $<0.0001$ \\
adj. R2 & 0.61 & & & \\
\hline
\end{tabular}

Rounded to two decimal places 
Table 9: Summary statistics

\begin{tabular}{|c|c|c|c|c|c|c|c|c|c|}
\hline Year & $\mathbf{N}$ & Mean & SD & Min & Q1 & Median & Q3 & Max & IQR \\
\hline \multicolumn{10}{|c|}{ Height (cm) } \\
\hline 1910 & 1281 & 168.2 & 6.6 & 140.5 & 164.0 & 168.5 & 173.0 & 192.5 & 9.0 \\
\hline 1920 & 1959 & 169.9 & 6.6 & 142.0 & 166.0 & 170.0 & 174.0 & 194.0 & 8.0 \\
\hline 1933 & 1790 & 171.4 & 6.6 & 129.0 & 167.0 & 171.5 & 176.0 & 197.0 & 9.0 \\
\hline 1940 & 3090 & 172.0 & 6.6 & 128.0 & 168.0 & 172.0 & 176.0 & 197.0 & 8.0 \\
\hline 1951 & 2594 & 173.4 & 6.2 & 150.0 & 169.0 & 173.0 & 178.0 & 194.0 & 9.0 \\
\hline \multicolumn{10}{|c|}{ Chest circumference $(\mathrm{cm})$} \\
\hline 1910 & 1281 & 85.9 & 4.7 & 68.0 & 83.0 & 86.0 & 89.0 & 107.0 & 6.0 \\
\hline 1920 & 1959 & 86.9 & 5.0 & 52.0 & 84.0 & 87.0 & 90.0 & 108.0 & 6.0 \\
\hline 1931 & 1790 & 88.4 & 4.8 & 68.0 & 85.0 & 88.0 & 91.0 & 112.0 & 6.0 \\
\hline 1940 & 3090 & 88.1 & 4.6 & 68.0 & 85.0 & 88.0 & 91.0 & 108.0 & 6.0 \\
\hline 1951 & 2594 & 90.0 & 4.5 & 65.0 & 87.0 & 90.0 & 93.0 & 116.0 & 6.0 \\
\hline \multicolumn{10}{|c|}{ Mid upper arm circumference $(\mathrm{cm})$} \\
\hline 1910 & 1281 & 25.1 & 1.9 & 19.0 & 24.0 & 25.0 & 26.0 & 37.0 & 2.0 \\
\hline 1920 & 1959 & 25.0 & 1.8 & 16.0 & 24.0 & 25.0 & 26.0 & 36.0 & 2.0 \\
\hline 1931 & 1790 & 25.7 & 1.8 & 19.5 & 24.5 & 26.0 & 27.0 & 34.0 & 2.5 \\
\hline 1940 & 3090 & 25.3 & 1.8 & 19.0 & 24.0 & 25.0 & 26.0 & 32.0 & 2.0 \\
\hline 1951 & 2594 & 25.8 & 2.0 & 19.0 & 24.0 & 26.0 & 27.0 & 38.0 & 3.0 \\
\hline \multicolumn{10}{|c|}{ Weight (kg) } \\
\hline 1933 & 1790 & 64.0 & 7.3 & 35.0 & 60.0 & 64.0 & 68.0 & 120 & 8.0 \\
\hline 1940 & 3090 & 61.2 & 7.1 & 29.0 & 56.0 & 61.0 & 65.5 & 95.0 & 9.5 \\
\hline 1951 & 2594 & 63.9 & 7.3 & 41.0 & 59.0 & 63.0 & 68.0 & 124.0 & 9.0 \\
\hline \multicolumn{10}{|c|}{ BMI (kg/m^2) } \\
\hline 1933 & 1790 & 21.8 & 2.0 & 16.2 & 20.4 & 21.6 & 23.1 & 35.8 & 2.7 \\
\hline 1940 & 3090 & 20.7 & 2.0 & 14.5 & 19.4 & 20.6 & 21.9 & 30.7 & 2.5 \\
\hline 1951 & 2594 & 21.2 & 2.1 & 15.7 & 19.8 & 21.1 & 22.3 & 41.4 & 2.5 \\
\hline
\end{tabular}

Table 10: BMI categories 1933 and 1951

\begin{tabular}{lcccc}
\hline \multicolumn{5}{c}{ BMI categories $(\mathbf{k g} / \mathbf{m} \mathbf{2})$} \\
Conscription year & $<\mathbf{1 8 . 5}$ & {$[\mathbf{1 8 . 5 - 2 5})$} & {$[\mathbf{2 5 - 3 0 )}$} & $>\mathbf{3 0}$ \\
\hline \multirow{5}{*}{$\mathbf{5 3 3}$} & 54 & 1642 & 90 & 3 \\
$\mathbf{1 9 5 1}$ & 162 & 2326 & 98 & 8 \\
& \multicolumn{5}{c}{ Conscripts } \\
$\mathbf{1 9 3 3}$ & 3.02 & 91.73 & 5.03 & 0.17 \\
$\mathbf{1 9 5 1}$ & 6.25 & 89.67 & 3.78 & 0.31 \\
\hline
\end{tabular}


Table 11: Literature equation estimation accuracy weight (kg)

\begin{tabular}{lcc}
\hline & $\begin{array}{c}\text { Test dataset } \\
\text { 1933-1938 }\end{array}$ & $\begin{array}{c}\text { Validation dataset } \\
1947-1951\end{array}$ \\
\hline Chittawanarat et al. 2012 estimation & & \\
Actual mean & 63.25 & 63.58 \\
Predicted mean & 65.06 & 67.19 \\
Difference & -1.81 & -3.61 \\
No. of values in a 10 percent range (in \%) & 78.59 & 60.09 \\
& & \\
Cattermole et al. 2017 estimation & & 63.58 \\
Actual mean & 63.25 & 51.94 \\
Predicted mean & 51.66 & 11.64 \\
Difference & 11.59 & 18.38 \\
No. of values in a 10 percent range (in \%) & 16.63 & \\
& & \\
Ostchega et al. 2004 estimation & & 63.58 \\
Actual mean & 63.25 & 47.56 \\
Predicted mean & 46.40 & 16.03 \\
Difference & 16.87 & 4.43 \\
No. of values in a 10 percent range (in \%) & 2.71 & \\
\hline
\end{tabular}

Table 12: Literature equation estimation accuracy BMI (kg/m2)

\begin{tabular}{|c|c|c|}
\hline & $\begin{array}{l}\text { Test dataset } \\
1933-1938\end{array}$ & $\begin{array}{c}\text { Validation dataset } \\
1947-1951 \\
\end{array}$ \\
\hline \multicolumn{3}{|l|}{ Benítez Brito et al. 2016 estimation } \\
\hline Actual mean & 21.49 & 21.14 \\
\hline Predicted mean & 22.31 & 22.37 \\
\hline Difference & -0.81 & -1.23 \\
\hline No. of values in a 10 percent range (in \%) & 79.43 & 64.98 \\
\hline \multicolumn{3}{|l|}{ Sultana et al. 2015 estimation } \\
\hline Actual mean & 2149 & 21.14 \\
\hline Predicted mean & 21.06 & 21.16 \\
\hline Difference & 0.43 & -0.02 \\
\hline No. of values in a 10 percent range (in \%) & 73.20 & 74.36 \\
\hline \multicolumn{3}{|l|}{ Powell-Tuck and Hennessy 2003 estimation } \\
\hline Actual mean & 21.49 & 21.14 \\
\hline Predicted mean & 21.16 & 21.23 \\
\hline Difference & 0.34 & -0.09 \\
\hline No. of values in a 10 percent range (in \%) & 88.02 & 88.40 \\
\hline \multicolumn{3}{|c|}{ Powell-Tuck and Hennessy 2003 estimation (age corrected) } \\
\hline Actual mean & 21.49 & 21.14 \\
\hline Predicted mean & 20.00 & 20.06 \\
\hline Difference & 1.51 & 1.08 \\
\hline No. of values in a 10 percent range (in \%) & 56.58 & 72.78 \\
\hline
\end{tabular}


Table 13: Mean values of anthropometric measurements for selected years

\begin{tabular}{|c|c|c|c|c|c|c|}
\hline \multicolumn{7}{|c|}{1939} \\
\hline & $\mathbf{n}$ & Height & Chest circ. & Upper arm circ. & Weight & BMI \\
\hline$<19$ & 1204 & 172.4 & 89.2 & 26.1 & 61.9 & 20.8 \\
\hline $19-20$ & 2046 & 171.7 & 88.8 & 26.1 & 62.4 & 21.2 \\
\hline $20-21$ & 233 & 173.7 & 86.4 & 25.3 & 60.2 & 20.0 \\
\hline$>=21$ & 72 & 174.1 & 86.6 & 25.1 & 60.6 & 20.0 \\
\hline \multicolumn{7}{|c|}{1929} \\
\hline$<19$ & 58 & 173.5 & 90.6 & 26.6 & & \\
\hline $19-20$ & 1367 & 170.5 & 88.7 & 25.9 & & \\
\hline $20-21$ & 798 & 170.5 & 88.9 & 26.0 & & \\
\hline$>=21$ & 184 & 171.6 & 87.3 & 25.3 & & \\
\hline \multicolumn{7}{|c|}{1928} \\
\hline$<19$ & 67 & 172.0 & 88.5 & 26.1 & & \\
\hline $19-20$ & 1072 & 170.4 & 87.8 & 25.6 & & \\
\hline $20-21$ & 1039 & 170.5 & 87.9 & 25.5 & & \\
\hline$>=21$ & 173 & 171.9 & 86.9 & 25.1 & & \\
\hline \multicolumn{7}{|c|}{1927} \\
\hline$<19$ & 48 & 171.9 & 88.2 & 25.5 & & \\
\hline $19-20$ & 841 & 170.4 & 87.5 & 25.4 & & \\
\hline $20-21$ & 1126 & 170.1 & 87.9 & 25.4 & & \\
\hline$>=21$ & 156 & 171.2 & 86.5 & 25.0 & & \\
\hline \multicolumn{7}{|c|}{1926} \\
\hline$<19$ & 36 & 169.3 & 88.7 & 26.2 & & \\
\hline $19-20$ & 617 & 170.7 & 88.3 & 26.4 & & \\
\hline $20-21$ & 1205 & 169.9 & 88.5 & 26.4 & & \\
\hline$>=21$ & 210 & 172.0 & 87.1 & 25.9 & & \\
\hline
\end{tabular}


Table 14: Estimated regression equation corrected for ages (training dataset 1933-1938)

\begin{tabular}{|c|c|c|c|c|}
\hline \multicolumn{5}{|c|}{ Weight estimation } \\
\hline & Estimates & SE & $\mathrm{t}$ value & $p$ value \\
\hline Intercept & -102.3 & 1.36 & -75.0 & $<0.0001$ \\
\hline Chest circ. & 0.5 & 0.03 & 33.8 & $<0.0001$ \\
\hline Upper arm circ. & 1.8 & 0.01 & 55.8 & $<0.0001$ \\
\hline Height & 0.4 & 0.01 & 56.1 & $<0.0001$ \\
\hline Age $19-20$ & -0.2 & 0.25 & -0.6 & 0.5400 \\
\hline Age 20-21 & -0.7 & 0.29 & -2.6 & 0.0107 \\
\hline Age $>=21$ & -0.6 & 0.34 & -1.7 & 0.0840 \\
\hline \multirow[t]{2}{*}{ adj. R2 } & 0.78 & & & \\
\hline & Estimates & SE & $t$ value & $p$ value \\
\hline Intercept & -102.5 & 1.32 & -77.4 & $<0.0001$ \\
\hline Chest circ. & 0.5 & 0.01 & 34.4 & $<0.0001$ \\
\hline Upper arm circ. & 1.8 & 0.03 & 55.8 & $<0.0001$ \\
\hline Height & 0.4 & 0.01 & 56.0 & $<0.0001$ \\
\hline \multirow[t]{3}{*}{ adj. R2 } & 0.78 & & & \\
\hline & \multicolumn{2}{|c|}{ BMI estimation } & & \\
\hline & Estimates & SE & $t$ value & $p$ value \\
\hline Intercept & 8.1 & 0.45 & 17.6 & $<0.0001$ \\
\hline Chest circ. & 0.2 & 0.00 & 34.2 & $<0.0001$ \\
\hline Upper arm circ. & 0.6 & 0.01 & 56.4 & $<0.0001$ \\
\hline Height & -0.1 & 0.00 & -37.6 & $<0.0001$ \\
\hline Age $19-20$ & 0.0 & 0.08 & -0.4 & 0.7068 \\
\hline Age 20-21 & -0.2 & 0.10 & -2.2 & 0.0302 \\
\hline Age $>=21$ & -1.0 & 0.12 & -1.2 & 0.2442 \\
\hline \multirow[t]{2}{*}{ adj. R2 } & 0.68 & & & \\
\hline & Estimates & SE & $t$ value & $p$ value \\
\hline Intercept & 8.0 & 0.44 & 18.1 & $<0.0001$ \\
\hline Chest circ. & 0.2 & 0.00 & 34.7 & $<0.0001$ \\
\hline Upper arm circ. & 0.6 & 0.01 & 56.5 & $<0.0001$ \\
\hline Height & -0.1 & 0.00 & -38.3 & $<0.0001$ \\
\hline adj. R2 & 0.68 & & & \\
\hline
\end{tabular}


Table 15: World War II equation estimation accuracy weight $(\mathrm{kg})$ and BMI (kg/m2)

World War II dataset

Weight $=$ Intercept + Chest + Arm + Height $($ WCAH $)$

Actual mean

62.04

Predicted mean

62.72

Difference

$-0.69$

No. of values in a 10 percent range (in \%)

93.62

$\mathrm{BMI}=$ Intercept + Chest + Arm + Height $(\mathrm{BMICAH})$

Actual mean

20.78

Predicted mean

21.08

Difference

$-0.29$

No. of values in a 10 percent range (in \%)

93.17 
Figure 7: Weight and BMI estimation for two age groups

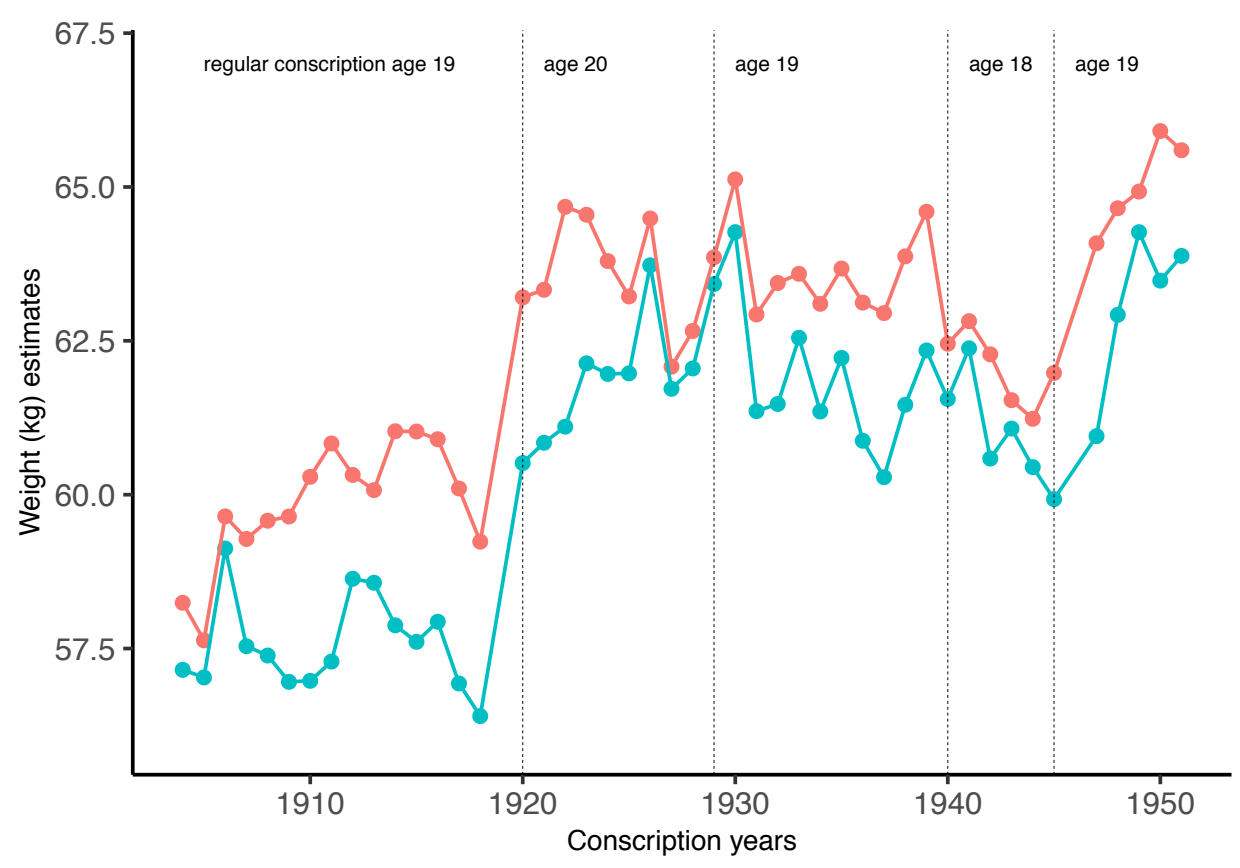

$\longrightarrow$ 19-20 $\rightarrow 20-21$

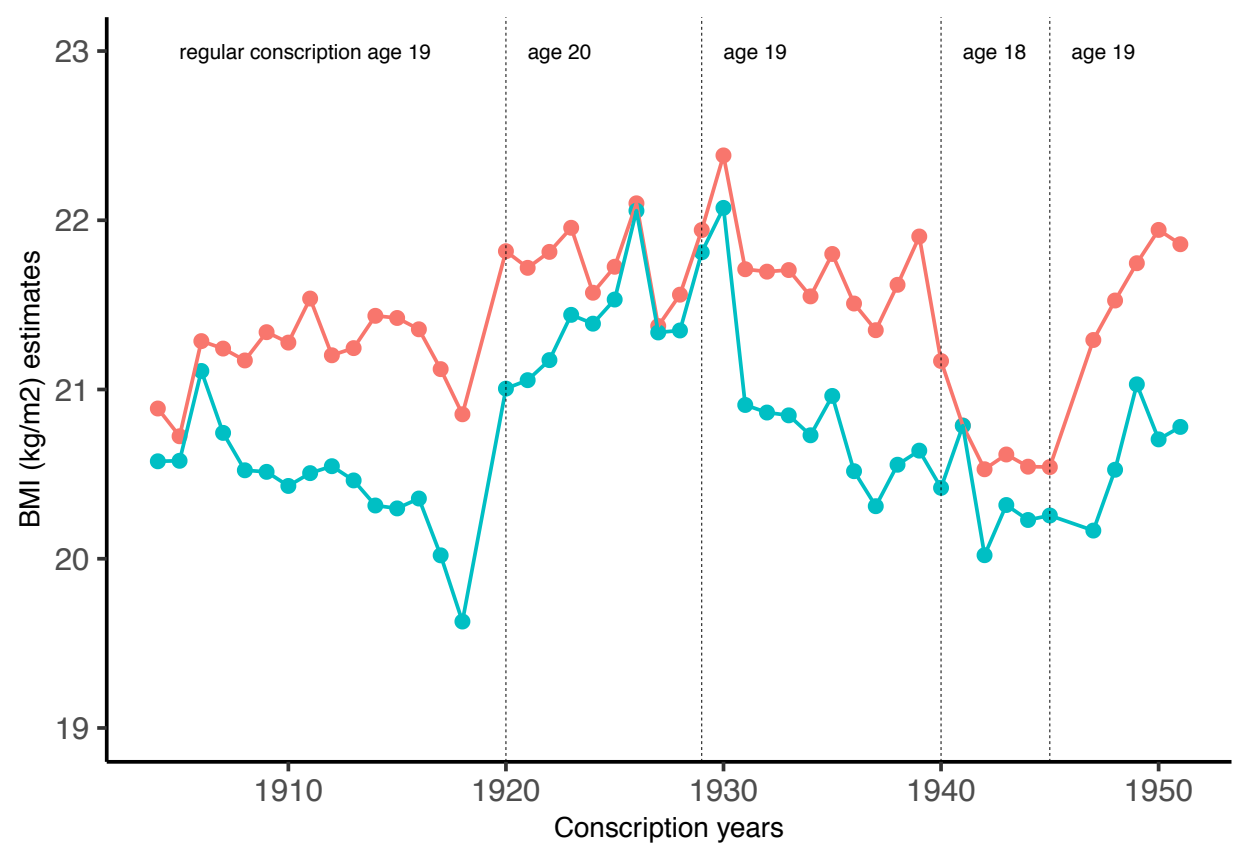

$\rightarrow-19-20 \rightarrow 20-21$ 
Figure 8: Scatterplot measured and estimated weight, test dataset 1933-1938 (WCAH equation)
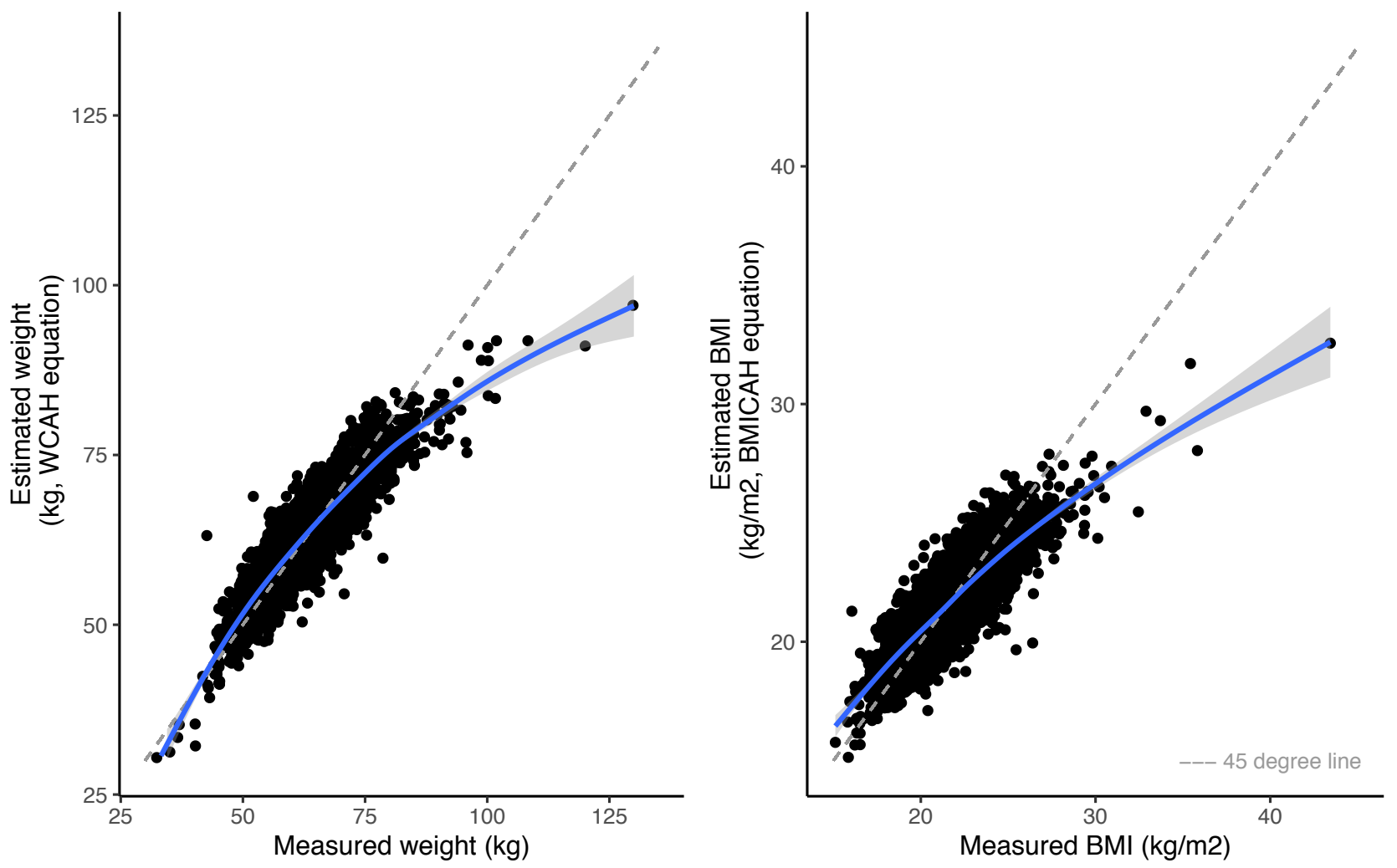

Figure 9: Weight and BMI Bland-Altman Plot, test dataset 1933-1938
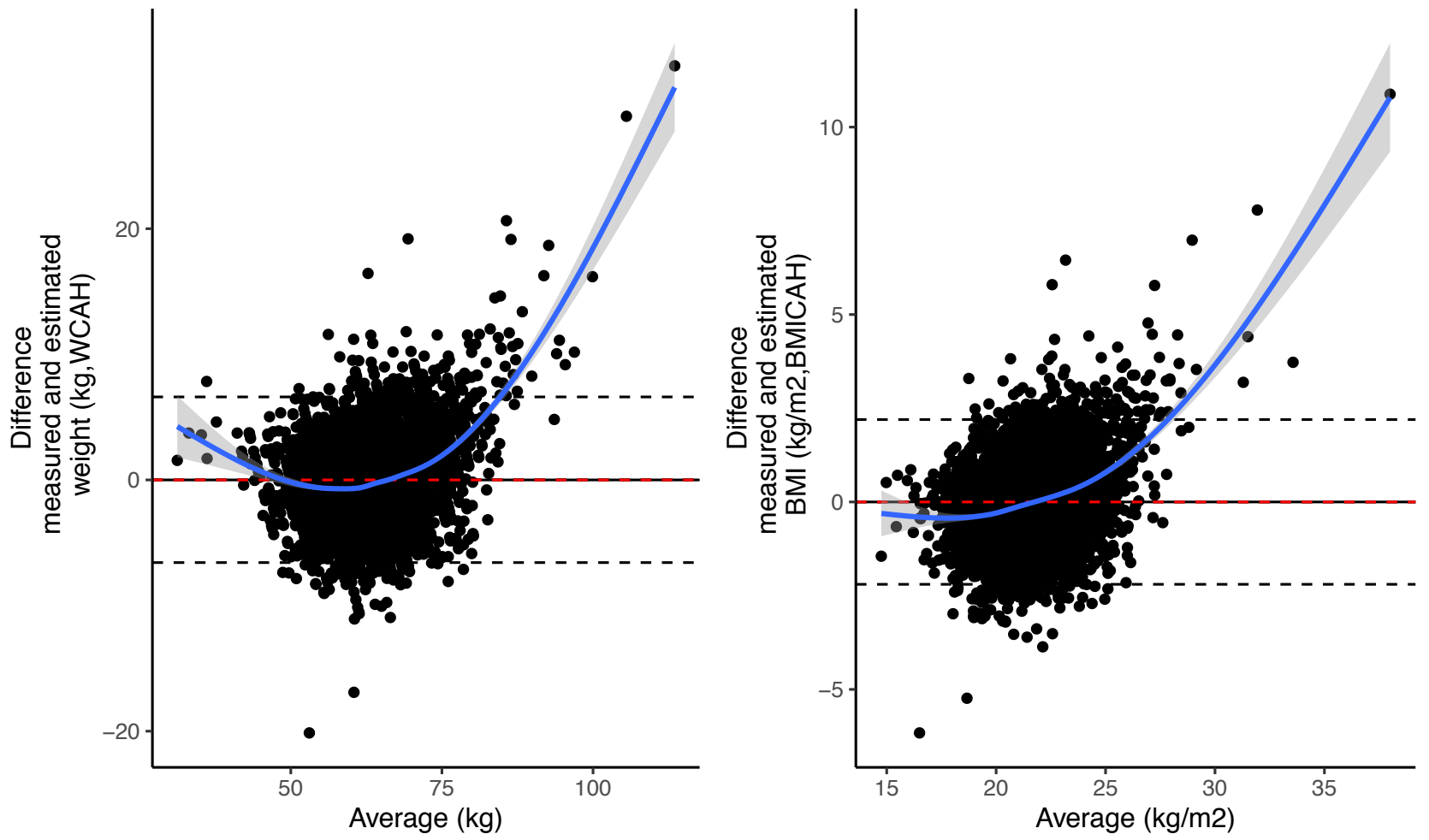
Figure 10: Density plots weight and BMI and estimated weight and BMI values 1933-1938 (test dataset)
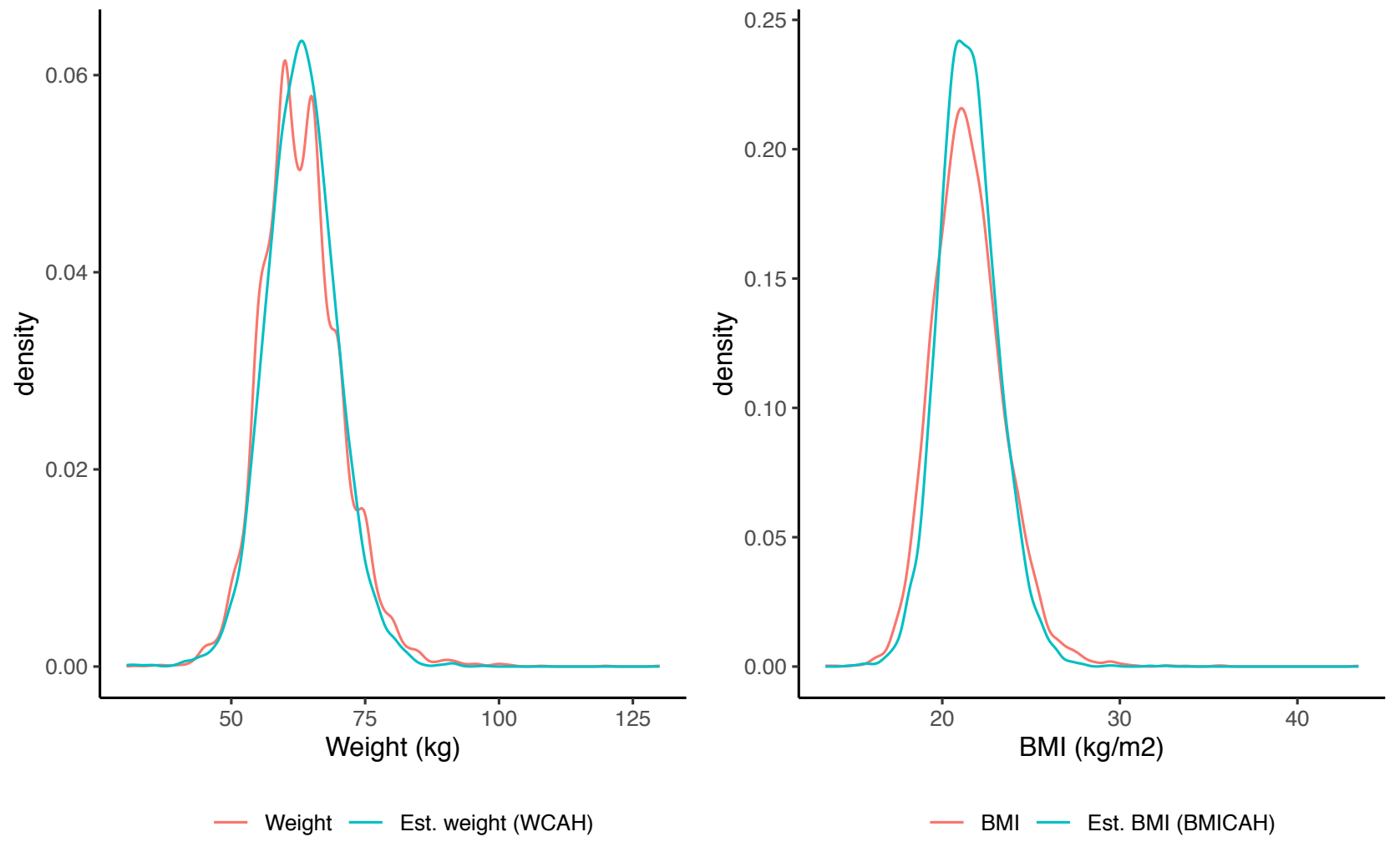
Figure 11: Histograms and kernel density estimation for height, chest circumference, mid upper arm circumference, weight and BMI 1933
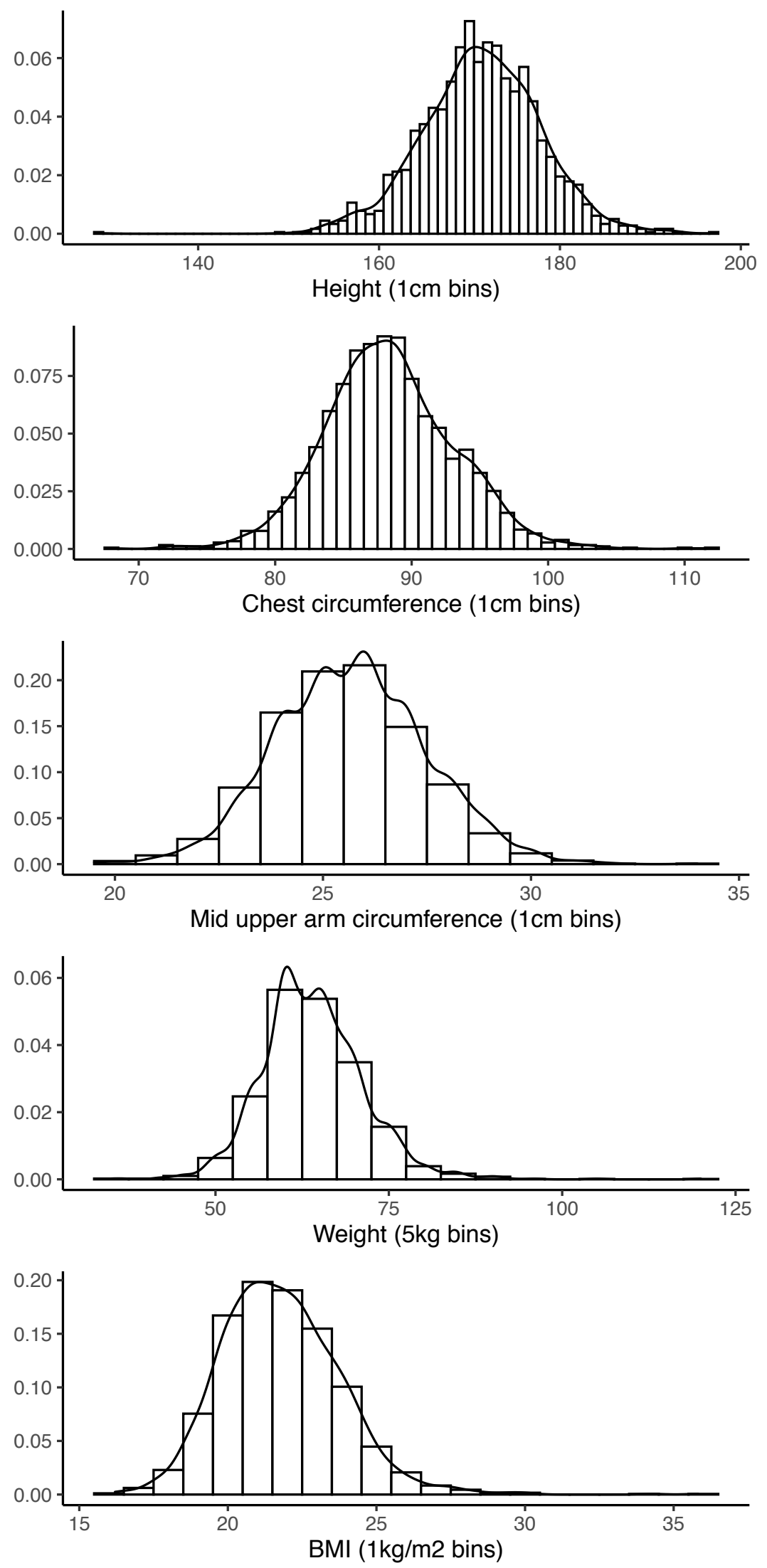